\title{
Stress and Obesity: Facilitation of Neuroendocrine and Autonomic Nervous System Recovery from Stress while Eating Comfort Foods?
}

\author{
Paula R. Prentice \\ West Virginia University
}

Follow this and additional works at: https://researchrepository.wvu.edu/etd

\footnotetext{
Recommended Citation

Prentice, Paula R., "Stress and Obesity: Facilitation of Neuroendocrine and Autonomic Nervous System Recovery from Stress while Eating Comfort Foods?" (2013). Graduate Theses, Dissertations, and Problem Reports. 4990.

https://researchrepository.wvu.edu/etd/4990

This Dissertation is protected by copyright and/or related rights. It has been brought to you by the The Research Repository @ WVU with permission from the rights-holder(s). You are free to use this Dissertation in any way that is permitted by the copyright and related rights legislation that applies to your use. For other uses you must obtain permission from the rights-holder(s) directly, unless additional rights are indicated by a Creative Commons license in the record and/ or on the work itself. This Dissertation has been accepted for inclusion in WVU Graduate Theses, Dissertations, and Problem Reports collection by an authorized administrator of The Research Repository @ WVU. For more information, please contact researchrepository@mail.wvu.edu.
} 
Stress and Obesity: Facilitation of Neuroendocrine and Autonomic Nervous System Recovery from Stress while Eating Comfort Foods?

Paula R. Prentice

Dissertation submitted to the College of Arts and Sciences

at West Virginia University

in partial fulfillment for the requirements for the degree of

Doctor of Philosophy

in

Psychology

Kevin T. Larkin, Ph.D, Chair

Amy Fiske, Ph.D

Amy Gentzler, Ph.D

Kimberly Kelly, Ph.D

Aaron Metzger, Ph.D

Department of Psychology

Morgantown, West Virginia

2013

Keywords: Stress, eating, comfort foods, physiological reactivity, heart rate, blood pressure 


\section{ABSTRACT \\ Stress and Obesity: Facilitation of Neuroendocrine and Autonomic Nervous System Recovery from Stress while Eating Comfort Foods?}

\section{Paula R. Prentice}

Obesity and dysfunctional eating are prevalent and costly concerns in the United States and throughout the world (CDC, 2007; Mathus-Vliegen et al., 2008). Research into the etiology of these conditions points to problems regulating eating, particularly during times of stress. The animal literature suggests that eating during and following stress may lead to a more immediate physiological recovery from stress (e.g., Bulwalkda et al., 2001; Pecoraro et al., 2004). The present study was designed to test this phenomenon in humans; that is, to determine if eating a favorite food immediately after stress would lead to enhanced physiological recovery from stress; and if so, for whom does the phenomenon occur? Fifty two young adults (13 men, 37 women; average age $=19.8$ years) completed an entrance survey and then were invited into the laboratory for two separate sessions. Participants engaged in a modified Trier Social Stress Test while physiological (heart rate, blood pressure, heart rate variability, salivary cortisol) and affective (PANAS) measures of reactivity and recovery were gathered. During one of the sessions (Food Session), participants ate a favorite food immediately following stress. A pairedsamples t-test comparing Food and No Food recovery showed a significant difference in recovery for heart rate, $t(52)=3.72, p<.001$, and systolic blood pressure, $t(48)=2.9, p<.01$ between the Food and No Food sessions; however, it was opposite of the predicted direction. Participants showed a slower heart rate and systolic blood pressure recovery during the Food session compared to the No Food session. Additionally, emotional eating scores were associated with slower systolic blood pressure recovery, $\beta=.31, t(47)=2.17, p<.05$. These results suggest 
that food does not improve physiological recovery time following stress, but that eating following stress may increase recovery time, especially for people with dysfunctional eating patterns, leading to poorer long-term health outcomes. 
Table of Contents

Introduction $\quad 1$

Obesity: Etiology and Sequelae $\quad 2$

The Physiology of Stress 3

$\begin{array}{lr}\text { Stress, Eating, and Obesity } & 6\end{array}$

$\begin{array}{lr}\text { Comfort Food as Self-Medication in Response to Stress } & 8\end{array}$

Statement of the Problem 15

$\begin{array}{ll}\text { Hypotheses } & 16\end{array}$

$\begin{array}{lr}\text { Method } & 18\end{array}$

$\begin{array}{ll}\text { Results } & 26\end{array}$

$\begin{array}{ll}\text { Discussion } & 34\end{array}$

$\begin{array}{ll}\text { References } & 49\end{array}$

$\begin{array}{lr}\text { Figures } & 59\end{array}$

$\begin{array}{ll}\text { Tables } & 63\end{array}$

$\begin{array}{ll}\text { Appendix A } & 77\end{array}$

$\begin{array}{lr}\text { Appendix B } & 86\end{array}$

$\begin{array}{lr}\text { Appendix C } & 87\end{array}$ 
Stress and Obesity: Facilitation of Neuroendocrine and Autonomic Nervous System Recovery from Stress following Eating Comfort Foods?

Nearly $70 \%$ of American adults are overweight or obese. Often, these problems arise at a young age; $25 \%$ of American children are overweight and at risk for becoming obese, and 29\% of young adults are obese (CDC, 2007; Crothers, Kehle, Bray, \& Theodore, 2009; Giacosa et al., 1999; Koebnick, Smith, Huang, Martinez, Clancy, \& Kushi, 2012; NIH, 1998). Similarly, approximately 150 million Europeans meet the criteria for obesity, and rates of overweight or obesity range from $40 \%-80 \%$, depending on the country (Tsigos, Hainer, Basdevant, Finer, Fried, Mathus-Vliegen et al., 2008). Although a range of genetic and environmental factors have been implicated in the dramatic increase in obesity observed over the past few decades, the mechanisms through which stress plays a role in the development of this pervasive health risk factor have not been clearly identified. The behavior undertaken in response to stress proves to be just as important in the development of obesity. In both animal and human models, stress has been implicated as a prominent factor in the development of obesity through increased consumption of high-calorie foods (e.g., Epel, Lapidus, McEwen, \& Brownell, 2005; Ulrich-Lai \& Herman, 2009), as well as an unhealthy cycle of restricting and binging. Half of young American women and one quarter of young American men reported being "on a diet" in one study, with 3-15\% reporting binge eating (Neumark-Sztainer, Wall, Larson, Eisenberg, \& Loth, 2011). Although eating specific high-calorie foods, often referred to as 'comfort foods,' has been shown to be associated with reductions in negative affect (e.g., Goldfield, Adamo, Rutherford, \& Legg, 2008), the relation between food intake and physiological profiles of stress recovery is less well-documented, and has been investigated primarily in animals. This study 
examined individual variability in the mechanisms through which comfort food consumption influences physiological recovery from exposures to stress in a sample of young adults.

\section{Obesity: Etiology and Sequelae}

The role of obesity in the development of multiple health risk factors is clear. The United States spends over $\$ 100$ billion annually to treat obesity-related disease (CDC, 2007; Giacosa, Franceschi, La Vecchia, Favero, \& Andreatta, 1999; NIH, 1998). Through its role as the “central and causal component" of metabolic syndrome (Furukawa, Fujita, Shimabukuro, Iwaki, Yamada, Nakajima et al., 2004, p. 1752), obesity is a significant factor in the development of cardiovascular, orthopedic, gastroenterological, pulmonary, and psychosocial diseases (Laederach-Hoffman, Mussgay, \& Ruddel, 2000). For this reason, a main goal of research has been to elaborate the etiology of obesity. Several factors seem to play a role in the development of this pervasive risk factor. Genetics, an obesogenic environment, culture, race, sex, and psychological factors have all been linked to unhealthy weight gain (Apovian, 2009).

Despite this epidemic, efforts to reduce consumption of high-caloric foods and increase engagement in physically active lifestyles have not been adopted by the majority of Americans. Based upon research finding abnormalities in autonomic and neuroendocrine functioning among obese persons (Rosmand, Dallman, \& Bjorntorp, 1998; Steptoe \& Wardle, 2005) and individuals with disorders involving binge eating (Vigo, Castro, Dorpinghaus, Weidema, Cardinali, Siri et al.., 2008), exposure to stress is thought to be an influential variable in explaining why unhealthy food consumption behaviors persist (Rowland \& Antelman, 1976; Telch \& Agras, 1996). If consumption of high-caloric foods enhances physiological recovery following exposure to mental stress, as often observed in animal studies (e.g., Bulwalda, Blom, Koolhaas, \& van Dijk, 
2001; Kinzig, Hargrave, \& Honors, 2008), it would help explain why consumption of such unhealthy foods persists among humans and leads towards expression of numerous disease consequences. In this regard, it is possible that consumption of unhealthy 'comfort' foods is negatively reinforced by the reduced physiological stress responding that occurs when one consumes these sorts of food. Although there is some evidence for this negative reinforcement cycle of eating certain types of foods using animal models, it is less clear whether consumption of unhealthy foods by humans modulates the intensity and patterning of the physiological stress response. The central aim of this project was to examine the stress-reducing properties of consuming 'comfort' foods.

\section{The Physiology of Stress}

Most definitions of stress distinguish the source of stress in the environment, called the stressor, from the effect it has on the body, called the stress response. The body's first reaction to presentation of a stressor is one of alarm (e.g., the fight-flight response). If the stressor persists, the alarm phase is followed by a stage of bodily resistance to stress in which the body adapts to the state of arousal needed to respond to the ongoing stressor. Finally, with continued exposure to the environmental stressor, the organism will reach the stage of exhaustion and bodily systems no longer function properly (Selye, 1993). The nature of this chain of events implies that the body's response to exposure to environmental stressors is finite and can eventually result in overall tissue and organ damage. Since the first exploration into the effects of stress on physiology, several pathways have been elaborated that are of interest in reference to stress and eating.

\section{The Hypothalamic Pituitary Adrenal (HPA) Axis}


When a stressor is present, the paraventricular nucleus $(\mathrm{PVN})$ of the hypothalamus is stimulated to send releasing hormones (e.g., corticotrophic releasing hormone) to the pituitary gland, from which ACTH is released to the adrenal glands. The final result of this cascade of events is the release of glucocorticoids (GCs; cortisol in humans, corticosterone in rodents). These GCs then influence other systems (e.g., the sympathetic nervous system) to respond to the stressor, while at the same time signaling the brain to terminate the HPA axis response. Hence, the HPA axis functions as a negative feedback system that, under normal conditions, stimulates the appropriate responses and then shuts itself down. Unfortunately, this system is negatively influenced by exposure to chronic stress and the resulting imbalance often leads to tissue and organ pathology (Adam \& Epel, 2007; Ulrich-Lai \& Herman, 2009).

\section{Sympatho-Adrenal Medullary (SAM) Response}

The SAM response is innervated by the sympathetic branch of the autonomic nervous system (ANS). It is responsible for influencing cardiovascular responses to stress (e.g., increased heart rate, increased blood pressure). This system is most closely linked to the acute stress response, because it is quickly dampened by the parasympathetic arm of the ANS (Ulrich-Lai \& Herman, 2009).

Through the continued actions of the SAM systems, exposure to chronic daily stress has deleterious effects on cardiovascular health by influencing the reactions of the autonomic nervous system. Studies have linked stress exposure, as well as the intensity of the reactivity response and prolonged recovery rate, to higher mortality (Sedova, Berube, Gaudet, Dumont, Tremblay, Hametet al., 2004). Although most of the early work examining stress-disease relations focused on the deleterious influence of exaggerated autonomic and neuroendocrine responses during exposure to stress (e.g., Matthews, Stoney, McCann, \& Manuck, 1986), more 
recent work has focused on the physiological disruptions resulting from delayed recovery rates that follow exposures to stress (e.g., Brosschot \& Thayer, 1998; Heponiemi, Elovainio, Pulkki, Puttonen Raitakari, \& Keltikangas-Jarvinen, 2007).

Although numerous measures of neuroendocrine and autonomic functioning have been employed in investigations involving exposure to stress, the most common indices have been cortisol and heart rate, respectively. Both are relatively easy to measure in laboratory environments and are known to react to the types of stress presentations used in human investigations. More recently, there has been significant interest in measuring heart rate variability (HRV), due to its known association with all-cause mortality (Tsuji, Venditti, Manders, Evans, Larson, Feldman, \& Levy, 1994). Additionally, measurements of HRV can be subjected to spectral wave form analysis to obtain indicators of autonomic nervous system functioning, including parasympathetic tone (Porges, 1995). In concert, by measuring these indices of the stress response, we know that the initial exposure to acute stress is accompanied by SAM activation, which can easily be detected by measuring heart rate, blood pressure, or some other parameter associated with autonomic arousal (e.g., skin conductance, pupil dilation). HRV measures can assist in distinguishing the relative contributions of the sympathetic and parasympathetic divisions of the autonomic nervous system response.

If the exposure to stress persists over time, increased GC activity can be detected either in the blood or saliva and cytokines in the immune system are activated. Continued exposure to stress then results in tissue and organ damage that presumably occurs in response to the prolonged SAM and HPA activation. Due to the length of time associated with documenting tissue damage and the obvious ethical concerns associated with causing tissue damage, laboratory studies of stress have focused on measuring the more proximal endpoints of intensity 
and duration of SAM and HPA response following relatively brief exposures to stress. In the current study, we used several measures of SAM (e.g., heart rate, blood pressure, and HRV) and one measure of HPA activation (e.g., salivary cortisol) to examine whether consumption of 'comfort' foods influenced these components of the stress response.

\section{Stress, Eating, and Obesity}

Several different bodies of literature provide evidence that stress is linked with overeating, which in turn is linked with onset of obesity. Some studies have shown that exposure to stress is associated with both onset of negative affect and overeating. There is also evidence that obese individuals have distinctive physiological stress responses when compared with persons of normal weight. In brief, each of these bodies of literature confirms that stress is linked with eating behaviors. Findings from studies comprising these bodies of literature will be summarized in the sections that follow.

\section{Environmental Stress Influences Food Intake}

The relation between stress and eating has been demonstrated in both human and animal models. Rowland and Antelman (1976) first demonstrated that daily chronic stress induces overeating, or hyperphagia, in their study of 24 adult female rats. The results of this study indicated that exposure to chronic stress in the form of a constant tail pinch increased intake of sweet milk and caused weight gain. Studies of the role of stress and negative affect in humans demonstrated similar results. For example, Telch and Agras (1996) found that obese persons with a binge eating disorder consumed twice as many calories as individuals without an eating disorder, and experienced more negative affect overall than non-binge eaters. When asked to explain the difference between "overeating" and "binge eating," study participants reported 
significantly more negative affect prior to something they classified as a "binge," regardless of caloric content. Patients with bulimia nervosa have also been shown to report significantly higher negative affect, desire to binge, and insecurity following exposure to achievement and interpersonal stress (Tuschen-Caffier \& Vogele, 1999). Overall, the literature outlines links among exposure to environmental stress, the experience of subjective negative affect, and overeating (Greeno \& Wing, 1994).

\section{Obesity and the Stress Response}

Autonomic abnormalities in response to stress have been documented in the obese (Valensi, Phan Thi, Lormeau, Paries, \& Attali, 1995). Research indicates that obese individuals have lower proportions of high frequency (HF) HRV, a marker of parasympathetic activity and vagal tone, compared to controls. In a study examining cardiovascular responses to mental stress in overweight and obese participants, results showed that, as BMI increased, HF HRV decreased. This indicated that obese individuals showed a withdrawal of parasympathetic activity during mental stress (Laederach-Hoffman, Mussgay, \& Ruddel, 2000) compared with non-obese controls. Additionally, several studies have reported a hyperactive hypothalamic-pituitaryadrenal (HPA) axis in obese men and women (Pasquali, Anconetani, Chattat, Biscotti, Spinucci, Casimirri, et al., 1996; Rosmand, Dallman, \& Bjorntorp, 1998). Women with visceral obesity have been shown to have a more hyperactive HPA response than women with subcutaneous obesity, resulting in higher levels of basal cortisol and greater HR reactivity during stress (Pasquali et al., 1996). These studies show a significant link between both obesity and abdominal adiposity and more intense responses to stress presentations. 
Investigations with both humans and animal models indicate that obesity affects recovery from stress, a known predictor of future cardiovascular health. Obesity exaggerates the effect of stressful events on the cardiovascular system, and is linked with a slower recovery (Sedova Berube, Gaudet, Dumont, Tremblay, Hamet et al, 2004). Persons with higher BMI and waist-tohip ratio (WHR) have impaired post-stress recovery of blood pressure and cardiac output. Longitudinal results of one study indicated that increases in WHR over three years predicted impaired recovery of SBP in men (Steptoe \& Wardle, 2005). This relation was emphasized in a study in which weight loss improved heart rate recovery in the first minute following a stressor in overweight and obese men (Brinkworth, Noakes, Buckley, \& Clifton, 2006).

Studies of animal models of obesity show similar effects on recovery. D’Angelo and colleagues (2006) compared the use of propranalol, a $\beta$-adrenergic blocker, to aid in recovery from stress in obese versus lean Zucker rats . Results indicated that obese rats had a more sustained mean arterial pressure during recovery, and that propranalol was effective in facilitating blood pressure recovery in lean but not obese rats. Sedova and colleagues (2004) investigated the link between diet-induced obesity and cardiovascular reactivity to and recovery from stress in spontaneously hypertensive rats. Results indicated that obese rats showed no differences in reactivity to stress, but that both HR and BP recovery were delayed in obese rats compared to normal controls. Investigations with both humans and animals indicate that obesity impedes physiological recovery from stress.

\section{Comfort Food as Self-Medication in Response to Stress}

Based upon knowledge that stress affects eating behaviors and that obese persons have impaired stress responses, researchers have begun testing the effects of food consumption on the 
physiological stress response in an attempt to explain why obese individuals continue harmful food intake when they experience stressful circumstances. Very little research has been done with humans investigating this question, whereas the literature using animal models (i.e., rats) is more developed. Animal models have been used to study the effects of comfort food on both the chronic and acute stress responses. Consequently, most of the literature described in the following section that has examined the question of interest in the current study (i.e., whether consumption of comfort foods actually provide some physiological relief when exposed to stress) has been done on animals. Studies have explored this research question using both exposures to chronic and acute environmental stressors.

\section{Comfort Food and the Chronic Stress Response}

One of the strengths of experimental studies using animal subjects is the ability to study long-term processes, such as chronic stress. Pecoraro and colleagues (2004) conducted one such study to test the idea that glucocorticoids directly stimulate the brain during chronic stress and exert indirect effects on peripheral energy stores. The authors used a 2 (stress: restraint stress v. no restraint stress) by 2 (food: comfort food v. no comfort food) design. Rats either had access to a diet rich in sucrose and lard (i.e., the designated comfort food), or a typical chow diet. Animals in the stress groups were exposed to restraint. Results showed that, during stress, the restrained group with access to comfort food increased intake of comfort food compared to the no-stress comfort food control. The restraint plus comfort food group showed reduced ACTH responses across stress days compared to the stressed group with no access to comfort food. Stressed animals with access to comfort food showed a significant reduction in corticosterone on the last day of measurement, and a trend in this direction on earlier days. 
Fachin and colleagues (2008) sought to determine whether chronic restraint influenced chocolate intake while measuring several physiological and behavioral outcomes. Adult Wister rats were assigned to one of four groups (chow, chow + chocolate, chow + stress, chow + stress + chocolate). Animals were maintained on their respective diet for 50 days, during which the stress groups were exposed to restraint. Stressed males ate less than control males overall; however, stressed females ate the same amount as controls, meaning that females did not show reduced eating associated with stress. Exposure to stress resulted in an increase in the size of the adrenal gland to body weight ratio, and females had larger adrenals for their body weight overall (indicating more stimulation via the HPA axis). However, females who ate chocolate showed smaller adrenal glands, implying that chocolate intake may have protected against an increase in adrenal gland weight in response to stress, but only among females.

Finally, Ulrich-Lai and colleagues (2007) sought to examine the relation between high and low calorie comfort foods and both acute and chronic stress responses (Ulrich-Lai et al., 2007). Male Long-Evans rats were trained to drink sucrose, saccharine (a no-calorie sweetener), or water for two weeks. Half of each group was then exposed to chronic variable stress for 14 days that resulted in reduced weight of the thymus and increased weight of the adrenals. The corticosterone response declined among control animals in the sucrose or saccharin drink conditions and in the stressed animals, but only those in the sucrose condition.

In summary, animal studies of the effect of consuming comfort foods when exposed to chronic stress have shown that the availability of comfort food throughout the duration of chronic stress may attenuate the physiological stress responses. Specifically, foods high in fat, sugar, or both have been related to decreased release of stress hormones and fewer changes in glands associated with the stress response. 


\section{Comfort Food and the Acute Stress Response}

Bulwalda and colleagues (2001) sought to determine whether a change in dietary macronutrients influenced behavioral and physiological stress response (Bulwalda, Blom, Koolhaas, \& van Dijk, 2001). Rats were given either a high carbohydrate (HC) or high fat (HF) diet and after three months underwent a social defeat stressor. Results showed that body temperature increased less in response to social stress for the HF group compared to the $\mathrm{HC}$ group. Additionally, locomotor activity of $\mathrm{HF}$ fed rats was less suppressed following exposure to stress compared to $\mathrm{HC}$ rats. Results related to serotonergic activity indicated that while there was no difference between the groups prior to social stress, HC-fed rats exhibited lower serotonin following exposure to hypothermic stress than HF-fed rats, suggesting that a high fat diet may have a protective effect on physiological and behavioral responses to stress (Bulwalda et al., 2001).

Kinzig and colleagues (2008) sought to determine the effects of inconsistent access to comfort food on the stress response (Kinzig, Hargrave, \& Honors, 2008). Rats were assigned to a diet either of normal chow or intermittent access to sweetened vegetable shortening for two hours per day on three (3D) or seven (7D) days per week for four weeks and exposed to one session of restraint stress. Two control groups of rats, one with unrestricted access to comfort food (UR) and one without (standard chow), were not stressed. Results showed that chow-fed and UR rats showed higher corticosterone reactions 30 minutes and 60 minutes after stress than 7D and 3D rats. Though the stressed animals ate significantly more than the unstressed animals, only the 7D group showed decreased food intake following stress. Finally, plasma leptin levels were significantly highest in the group with the UR diet. Leptin is a hormone released by adipose 
(fat tissue) that is responsible for communicating satiety. It also stimulates the HPA axis, and results in increased release of corticosterone in rats (Kinzing et al., 2008).

The few studies examining this phenomenon in humans have tested the effect of comfort food on reactions to acute stress. Markus and colleagues conducted a series of experiments investigating the influence of comfort food on the acute stress response (Markus et al., 1998, 2000, 2007). In the first study in this series, the investigators sought to determine whether carbohydrate-rich, protein poor food prevented a deterioration of mood and performance in vulnerable subjects participating in a laboratory stressor (Markus, Panhuysen, Tuiten, Koppeschaar, Fekkes, \& Peters, 1998). The authors hypothesized that intake of carbohydraterich/protein poor (CR/PP) food compared with protein-rich/carbohydrate poor (PR/CP) food would result in a protective effect against mood and performance deterioration for participants who were high in stress sensitivity. A large sample of university students $(\mathrm{N}=331)$ completed the Inadequacy (IN) Scale of the Dutch Personality Inventory. Participants scoring in the highest and lowest quartile were invited to the laboratory study. The IN is an index of neuroticism, which in turn has been linked to higher levels of stress sensitivity; therefore, the authors used this measure to create groups of high stress-prone (HS) and low stress-prone (LS) participants. Fortyeight participants (13 men, 35 women) completed a two-day laboratory procedure employing a mental arithmetic stressor with uncontrollable noise distraction. Specifically, participants were asked to subtract serially from a large number while being distracted by a noise that was out of their control. Changes in affect were assessed using a shortened version of the Profiled of Mood States (POMS), Dutch version. Participants consumed both diets (CR/PP and PR/CP), counterbalanced across experiment days, and completed a memory task. Heart rate, skin conductance, and salivary cortisol were collected on both study days. Results showed that the 
$\mathrm{CR} / \mathrm{PP}$ diet was associated with less depression, and increased vigor for the HS group. There was a main effect of stress condition (stress or no stress resting period) on HR, skin conductance, and cortisol. Most relevant to the proposed study, results showed that the CR/PP diet was related to a trend toward a protective effect against cortisol reactivity for HS but not LS participants.

The second study in this series (Markus, Panhuysen, Tuiten, \& Koppeschaar, 2000) used similar methods to the previous study. This study was designed to determine if a CR/PP diet would reduce affective and cortisol changes to a laboratory stressor in a high stress-prone sample (Markus et al., 2000). Participants $(\mathrm{N}=334)$ completed the IN, and the highest- and lowestscoring quartiles were invited to participate in a two-session experimental study. Participants (N $=45 ; 11$ men, 34 women) were again asked to consume a CR/PP diet or a PR/CP diet, counterbalanced across days, and were exposed to a stressor while HR, skin conductance, and cortisol measurements were taken. Affect was assessed via the POMS. The stressor was alternated between a controllable and uncontrollable noise distraction during mental arithmetic. Similar to the previous study, participants completed serial subtraction while a distracting noise was played. At some points in the experiment, participants had control over whether the noise was present and the intensity of the noise. Results revealed that consumption of the PR/CP diet showed a protective effect on affective changes for HS participants compared to LS participants. For cortisol, results showed a significant three-way interaction (stress-proneness by diet by stress). Specifically, consumption of the CR/PP diet, but not a PR/CP diet, was associated with a decrease in cortisol in response to stress for HS participants. No effect on cortisol was observed for participants in the LS group.

The most recent study by Markus was a double blind, placebo-controlled investigation to determine the influence of carbohydrates and tryptophan (TRP) on performance under stress 
(Markus, 2007). TRP is a macronutrient and amino acid that is one of the precursors to serotonin production that is often found in carbohydrates. It was hypothesized that performance under stress would improve after intake of a high-carbohydrate beverage but not following intake of a placebo beverage, because of increases in TRP. Physiological stress-response data were also collected and analyses were conducted to assess the protective effect of food intake on the stress response. Thirty-seven participants ( 8 men, 29 women) completed two experimental sessions during which they consumed one of two drinks (high carbohydrate or placebo) and were exposed to a stressor. Specifically, participants completed a computer task with instructions that varied over time. During this task, the participant's hand was occasionally exposed to icy water (cold pressor task). Mood, HR, skin conductance, and cortisol measures were assessed throughout both sessions. Blood samples were taken before the stressor to assess TRP levels. Results revealed significant main effects of diet on plasma TRP; specifically, the high carbohydrate drink resulted in higher plasma levels of TRP than the placebo. There were main effects of stress on mood, indicating that mood deteriorated during stress. Main effects of diet on mood showed that vigor increased, and fatigue declined, following intake of the carbohydrate drink but not with the placebo. Interestingly, results of task performance (reaction time) showed a significant increase in reaction time after placebo intake, while carbohydrate intake did not result in this increase. Finally, results revealed no effect of diet on cortisol. Cortisol levels significantly increased as a result of stress, regardless of diet (Markus, 2007).

Epel and colleagues (2001) sought to examine the relation between eating immediately following a stressor and the physiological stress response. Specifically, the study was designed to determine if cortisol reactivity was linked to food intake following stress (Epel, Lapidus, McEwen, \& Brownell, 2001). It was hypothesized that high reactivity would lead to eating more 
calories and more sweet, high fat food after stress. To test this hypothesis, 59 healthy premenopausal women (30-45 years) were recruited from the community. Participants completed three days of a laboratory stress paradigm and one control session. Each stress session consisted of a rest period, a stressor, and a recovery period during which food was available. During a modified version of the Trier Social Stress Test (TSST), participants were asked to prepare a speech and present this in front of judges, then complete serial subtraction in front of judges. Cortisol was measured eight times throughout the course of each session, and participants completed the POMS to assess mood reactivity to the stressor. Cortisol curves were correlated with food intake following stress. Results showed that "high cortisol reactors consumed more calories on the stress day compared to low reactors, but ate similar amounts on the control day" (Epel et al., 2001, p. 37). Additionally, results revealed that high reactors consumed more calories and servings on the stress day than the rest day. This was one of the first studies to demonstrate a link between a neuroendocrine marker and food intake following exposure to stress in humans; however, this study did not investigate the effect of food intake on the recovery of cortisol levels following stress exposure. Additionally, this study did not include assessment of cardiovascular recovery measures, and did not include men.

\section{Statement of the Problem}

Although the research cited above clearly indicates that there is an interaction between exposure to stress, food intake, and obesity, it is unclear how these factors interact to influence the magnitude and patterning of neuroendocrine and autonomic responses that occur during and following stress exposure. The animal studies described above suggest that consumption of comfort food is associated with an attenuated chronic stress response. Additionally, the attenuating effect of comfort food on the acute stress response shows promise in studies with 
animals, but results are far from conclusive. Finally, research does not yet support the existence of this effect with humans under acute or chronic stress. The series of studies by Markus and colleagues considered the influence of both individual characteristics and macronutrients (e.g., fat) on the stress response. Though the first studies in this series (Markus et al., 1998; Markus et al., 2000) supported an attenuating effect of food intake on the stress response, they also had several methodological limitations. The final study (Markus, 2007) used a stronger design, but did not find evidence for an attenuating effect of food consumption. Epel and colleagues (2001) found that high cortisol reactivity was linked with greater caloric intake during stress. Although this was a well-designed study that incorporated several cortisol measures, rigorous exclusion criteria and controls, and an internally and ecologically valid stressor, the study was designed to test the idea that stress reactivity resulted in eating, and mentioned but did not test the hypothesis that food influenced the stress response. In sum, research still needs to be conducted to clarify the nature of the potential attenuating effect of comfort foods when consumed by humans in response to stress.

In a summary of the literature pertaining to the sensory, physiological, and psychological pathways through which food and affect are related, Gibson (2006) concluded: "Future research should try to characterize more reliably the predictive traits, and psychophysiological mechanisms, underlying the link between food choice and mood" (p. 58). The goal of this study was to pursue this recommendation by examining the neuroendocrine and autonomic foundations of the propensity for consuming comfort food under stress.

\section{Hypotheses}

\section{Hypothesis One}


Based upon previous work with animals (e.g., Ulrich-Lai \& Herman, 2009) it was hypothesized that recovery of the physiological stress response will occur more rapidly following consumption of comfort food than when food is not consumed.

\section{Hypothesis Two}

Based upon the previous work with humans (Goldfield, Adamo, Rutherford, \& Legg, 2008; Markus et al., 1998; Markus et al., 2000), it was hypothesized that the magnitude of reduced negative affect (i.e., "comfort") that occurs following comfort food intake and exposure to acute stress would be associated with a more efficient recovery of the neuroendocrine and autonomic nervous system responses to stress during the Food session compared to the No Food session.

\section{Hypothesis Three}

Based on previous work with humans (e.g., Goldfield, Adamo, Rutherford, \& Legg, 2008; Markus et al., 1998; Markus et al., 2000), it was predicted that several markers of dysfunctional eating habits would be correlated with differential rates of recovery from stress observed between the session when comfort foods were consumed versus the session where no food was consumed. Given that people often report an emotionally comforting effect of eating following stress, emotional eating was a variable of particular interest. It was hypothesized that participants who reported a pattern of emotional eating would demonstrate a more enhanced recovery effect when consuming food during recovery compared to no food during recovery. Additionally, it was hypothesized that body mass index, waist hip ratio, depressive symptoms, negative affect, and symptoms of restrained and binge eating would be positively related to an 
accelerated recovery of neuroendocrine and autonomic responses to stress following food intake compared to recovery without food intake. These hypotheses were based on prior research showing reactivity differences of persons differing on BMI status (e.g., Pasquali et al., 1996; Rosmand et al., 1998), depression/mood status (Chida \& Hamer, 2008; Goldfield et al., 2008), and among persons with increased propensities for developing eating disorders (e.g., Vigo et al, 2008).

\section{Method}

\section{Participants and Sample Size}

Participants were 52 young adults ( 13 men, 37 women; average age $=19.8$ years). The sample racial composition was as follows: $84.6 \%$ White, $3.8 \%$ Black or African American, $3.8 \%$ Biracial, $1.9 \%$ Asian, and 1.9\% American Indian or Alaskan Native. (See Table 1 for additional sample information). Participants were excluded if they had a history of chronic health problems that could interfere with dependant variables (e.g., heart disease, respiratory disease, etc...), smoke or use smokeless tobacco at least once daily, or were currently taking any medications that might affect heart rate, blood pressure, or could result in falsely elevated cortisol levels (e.g., beta blockers). Participants were asked to refrain from using alcohol for 12 hours prior to each experimental session, eating a large meal, using caffeine, or exercising vigorously for two hours prior to each session.

Although 52 participants completed the study, consent to participate was obtained from a total of 70 volunteers. The remaining 18 only completed one experimental session and failed to return for the second session despite making several attempts to re-schedule them. Completers 
were compared with non-completers on pertinent variables and found not to differ/differ on sex (chi square), race, BMI, years of college, and health behaviors.

\section{Experimental Design}

This study employed a quasi-experimental design, using both regression analyses and within subjects comparisons. For the within subjects portion, related to Hypothesis One, participants' physiological recovery from stress was compared in two experimental situations (no food consumption during stress recovery vs. food consumption during stress recovery). For the regression portion of the study, predictor variables included change in negative affect following stress with and without food, body mass index (BMI), waist- to- hip ratio (WHR), history of binge eating, depressive symptoms, self-reported restrained eating, and emotional eating. Outcome variables for both analyses were area under the curve measurements during the recovery period for the following variables: heart rate (HR), systolic blood pressure (SBP), diastolic blood pressure (DBP), high frequency heart rate variability (HF HRV), low frequency heart rate variability (LF HRV), and salivary cortisol.

\section{Measures}

Cardiovascular measures. Heart rate was continually monitored during the experiment utilizing a Polar heart rate monitor Model RS800cx (Lake Success, New York). The Polar monitor has been previously validated in the assessment of heart rate during mental laboratory stress tasks (Goodie, Larkin, \& Schauss, 2000). This device consists of a sensor that detects ECG signals and is strapped around the participant's chest and a receiver that is connected to a computer located in an observation room where the experimenter monitored data acquisition. Continuous strings of interbeat intervals were generated for rest, task, and recovery periods. Data were subjected to spectral analysis for purposes of determining mean heart rate variability using 
the Kubios Heart Rate Variability Analysis Software program, Version 2.1. The HRV Analysis Software program has been shown to estimate valid parameters of heart rate variability (Niskanen, Tarvainen, Ranta-aho, \& Karjalainen, 2002). Blood pressure measurements were taken every two minutes throughout the two sessions (see Figures 1 and 2) with an IBS SD-700A automated sphygmomanometer (Waltham, MA). This device measures blood pressure via an occluding cuff that contains a microphone for detecting Korotkoff sounds positioned on the participant's left arm. Measures of SBP and DBP were displayed digitally and recorded by the experimenter.

Neuroendocrine measure. Salivary cortisol was collected at four points (see Figure 1) throughout Session One and four points (see Figure 2) throughout Session Two using Salivette synthetic swabs for cortisol determination. Saliva was collected by instructing participants to gently chew a Salimetrics oral swab for less than one minute to obtain a sample of .5-1 ml of volume. Following collection, swabs were be labeled with date and time of collection. They were frozen within four hours of collection as per salivary cortisol storage recommendations (Kirschbaum \& Hellhammer, 1989; Salimetrics, LLC). Each sample was analyzed for cortisol content using an Eagle Biosciences high sensitivity salivary cortisol enzyme immunoassay kit (Eagle Biosciences, Boston, MA) and a Biotek Synergy HT Multi-detection Microplate Reader at $450 \mathrm{~nm}$. Data from 51 participants were included in the analyses, resulting in 816 samples (408 samples in duplicate). Values for 60 samples (7\%) that were lost or unable to be analyzed were imputed using data from either the rest or recovery as follows. If a resting measure was missing for one session ( $\mathrm{n}=20$ samples), the mean of the resting measure from the other session was used as the best estimate of resting cortisol. If a measure of cortisol was missing during the 
recovery period (40 samples), it was imputed using values of the closest available recovery measure(s).

Self-report measures. To assess for individual differences in stress, eating patterns, and affective changes in response to stress, participants completed the following measures.

Demographics. Participants completed a questionnaire asking relevant demographic information (age, sex, socioeconomic status, etc.), health history, and health behavior information (see Appendix A).

Preferred Foods. To determine food preferences, participants were asked the following questions "What are your preferred snack foods?" and "Please list up to five foods you would classify as "comfort" foods."

Binge eating Patterns: Questionnaire of Eating and Weight Patterns (QEWP). Selected questions from the QEWP were used to assess binge eating behavior in the past six months (Spitzer, et al., 1992). This questionnaire is based on the Diagnostic and Statistical Manual III-R criteria for Binge Eating Disorder (BED) and has been used to aid in the diagnosis of BED and several categories of non-clinical binging: episodic overeating, binge eating, binge eating syndrome, and binge eating syndrome and distress (Nangle, Johnson, Carr-Nangle, \& Engler, 1994). Moderate stability of this measure has been demonstrated for purposes of categorizing participants based on their patterns of binge eating when administered twice over a three week period $(\kappa=.57)$. This measure has been validated with a college sample consisting of primarily Caucasian female students; score ranges were consistent with those reported in previous samples (Spitzer, et al., 1992). 
Depression: Center for Epidemiologic Studies Depression Scale (CES-D). The CES-D consists of 20 items assessing symptoms of depression. Participants were instructed to indicate how often they have felt a certain way in the past week on a 4-point scale. This measure is widely used to assess depressive symptoms in research, has been validated on a range of populations, including college students (Shean \& Baldwin, 2008), and demonstrates strong internal consistency (Cronbach's $\alpha$ 's $=.86-.92)$ and test-retest reliability ( $r$ 's $=.45-.70)$ (Radloff, 1977).

Other eating patterns: Dutch Eating Behavior Questionnaire (DEBQ). The DEBQ was created in order to measure eating behavior patterns (van Strien, Frijters, Bergers, \& Defares, 1986). This 33-item measure consists of three scales that measure restrained, emotional, and external eating. All scales have been shown to exhibit good internal consistency (Cronbach's $\alpha$ 's $=.80-.95)$.

State affect: Positive and Negative Affect Scale (PANAS). The PANAS is a 20-item self-report measure that results in two scales of affect: positive and negative (Watson, Clark, \& Tellegen, 1988). It can be used to measure more long-term affect or more immediate, "state" affect by varying the instructions given at the beginning of the measure. The measure demonstrates adequate convergent validity with measures of psychopathology (e.g., negative affect $r=.56$ with Beck Depression Inventory with instructions over the "last few days"). In general, the scale is reliable, precise, and the positive and negative affect scales are mostly independent measures of mood (Watson, Clark, \& Tellegen, 1988).

\section{Experimental Task}

The experimental task selected for this study is a modified version of the Trier Social Stress Test (TSST; Kirschbaum, Pirke \& Hellhammer, 1993). This task has been shown to result 
in increases in salivary cortisol, heart rate, and subjective measures of stress across numerous samples (e.g., Kirschbaum, Wust, \& Hellhammer, 1992; Hellhammer \& Schubert, 2012). Participants were given ten minutes to prepare a speech according to task instructions. Each participant then delivered a five-minute speech while his or her image was displayed in a monitor adjacent to the video camera. Participants were given instructions for one of two speeches of equal intensity at each session (job candidate and speeding ticket; see Appendix B); speech topics were counterbalanced across sessions. Following this speech, participants engaged in five minutes of mental arithmetic (serial subtraction) while simultaneously being videotaped. If participants made a mistake, they were interrupted and informed that a mistake was made ("that's incorrect, please begin again from ,") and were given the number of the last correct subtraction. The social evaluative nature of this task has been shown to elicit substantial physiological responses to stress and mimics the type of daily stress that leads to sympathetic arousal and risk for long-term disease.

\section{Procedure}

Recruitment. The study was titled "Cardiovascular Responses to Food" and participants were recruited via paper fliers, informed of the study in classes, and it was listed among studies in which students could participate for extra credit. Fliers read "Are you interested in getting extra credit in your psychology course? Would you like to earn $\$ 10.00$ ? Would you like to eat one of your favorite foods for free? If your answer is "YES," sign up for Cardiovascular Responses to Food: A Two-Part Lab Study" and included instructions for completing the screening. The fliers also specified that this was a research study, participants must be at least 18 years old, and that IRB approval is on file. 
Screening Phase. Following a brief computerized informed consent procedure, participants completed a screening questionnaire and self-report measures via an online survey administration system (SONA). The screening survey also included an evaluation of participants' food preferences (typical snack foods and things they described as "comfort foods"). Following the invitation to participate in the laboratory portion of the study, participants were asked which of the foods they indicated in the survey they would prefer to eat.

Experimential Sessions. Participants attended two experimental sessions conducted approximately one week apart. All sessions were conducted after 1:00 PM, because cortisol levels vary in a diurnal fashion and research suggests that cortisol levels reach a relatively steady state by the early afternoon (e.g., Kirschbaum \& Hellhammer, 1989). Therefore, any change in cortisol seen during the afternoon or early evening can more likely be attributed to experimental manipulations. Sessions were virtually identical except that participants consumed their designated comfort food in one session and consumed no food in the other session. Half of the participants completed the No Food Session first and the remaining participants completed the Comfort Food Session first.

Upon arrival at the first session, participants were greeted by the experimenter, and given a brief summary of the study. Then, they were informed that their participation in this study was voluntary and may advance the understanding of psychological constructs and improve public health. Participants who agreed to take part in this study were asked to sign an approved statement of informed consent which also explained that identifying health information will be handled confidentially. Following a screening for exclusion criteria (e.g., recent vigorous exercise), height, weight, and waist to hip ratio data were collected. Female participants provided 
a verbal assessment of menstrual phase and intake of oral contraceptive medication, as these variables have been shown to be related to cortisol level (Kirschbaum \& Hellhammer, 1989). During both sessions, participants were escorted to an experimental room in the Behavioral Physiology Laboratory where they were instructed how to secure the Polar monitor sensor to their chest. When the participant had the sensor in place, he or she alerted the experimenter, who then tested the equipment to ensure that the monitor was functional. Next, the participant was seated in a comfortable laboratory chair, and an occluding cuff was positioned over the brachial artery of the participant's left arm.

Rest Period. During rest periods for each session, participants were instructed to keep their feet flat on the floor for a 15 minute rest period. Heart rate was collected continuously throughout the rest period and blood pressure measurements began at 8 minutes into the rest period, and measures were taken every two minutes throughout the remainder of the period. A salivary cortisol sample was obtained after ten minutes of the rest period had elapsed. Following the rest period, the participant reported his or her mood state by completing the PANAS.

Task. During each session, when the rest period was completed, the experimenter provided the instructions for the Trier Social Stress Test. Participants had ten minutes to prepare their speech followed by the five min speech. Upon completion of the speech, participants were instructed to begin serial subtraction by sevens beginning at 9,000. They continued subtracting over the next 5 min period of time. The total task duration (speech delivery + mental arithmetic) was 10 min. Heart rate was measured continuously and blood pressure was taken every two minutes during the Trier Social Stress Test. 
Recovery Period. During each session, after the task, a 15-minute recovery period ensued in which cortisol samples were collected on three occasions (minutes 1, 8, and 15 of the recovery period), heart rate was measured continuously, and blood pressure measurements were taken every two minutes. At the beginning of the recovery period, participants completed a stress rating of the task on the 5 -point scale $(0=$ not at all stressful, $4=$ extremely stressful $)$ that has been used in previous stress studies (Gianaros et al., 2008). Additionally, participants reported their mood using the PANAS at the beginning and end of the recovery period.

During the Comfort Food Session, the Recovery Period was modified to permit consumption of the designated comfort food. In all other respects, the session was identical to the No Food Session. During the first five minutes of the Recovery Period, each participant was provided and consumed their designated comfort food while alone and unobserved. The food the participant chose was weighed, and participants were given the food during the Recovery Period just following completion of the stressor and PANAS. Following a five minute "eating period," the remaining food was removed and weighed.

Upon completion of each session, the experimenter removed the occluding cuff and left the monitoring room to allow the individuals to remove the Polar sensor. At the end of the second session, participants received extra credit in their Psychology class as well as five dollars per session.

\section{Results}

\section{Data Reduction}


Prior to data analyses, physiological parameters were examined and artifacts or inaccurate values were removed. For blood pressure, only blood pressure measurements that fell within the criteria outlined by Marler and colleagues (1988) were retained. These criteria indicate that SBP measurements greater than $250 \mathrm{~mm} \mathrm{Hg}$ or less than $70 \mathrm{~mm} \mathrm{Hg}$ and DBP measurements greater than $150 \mathrm{~mm} \mathrm{Hg}$ or less than $45 \mathrm{~mm} \mathrm{Hg}$ should be excluded from analyses. Additionally, Marler and colleagues suggest eliminating measurements in which the difference between SBP and DBP is too small to be an accurate measurement of normal pressure. The data for the present study were visually examined for consistency across measurement periods, and subjected to tests of the Marler criteria to verify valid measurement. In the present study, a total of 5 SBPs $(.3 \%$ of all SBPs measured) and 6 DBPs (.6\% of all DBPs measured) fell outside of the specified guidelines. These measurements were replaced with the mean of the SBP or DBP measures for the remaining minutes of that period.

Heart rate data were also examined prior to data reduction. Data were cleaned using an error correction feature within the Polar data acquisition software program. The error correction tool works by substituting abnormally high or low, invalid heart rate measurements with measurements that more accurately approximate heart rate at that time. Heart rate was collected continuously throughout each experimental session. For each session, approximately 551 measures of heart rate occurred per participant. On average, values of 40 heartbeats were replaced per participant, resulting in a small proportion (approximately $7.26 \%$ ) of substitutions per participant.

Once all artifacts were eliminated, cardiovascular measures were reduced using the following strategies. During each rest period, blood pressure and heart rate (SBP, DBP, and HR) 
values were averaged across the last five minutes of the rest period. Values from the duplicate cortisol assays conducted on the saliva sample obtained during each rest period were averaged to obtain a single cortisol value for each session's rest period. Finally, interbeat intervals (IBIs) for the full five-minute rest period were subjected to spectral analysis to obtain resting measures of HRV, because valid HRV measures cannot be obtained on samples of shorter durations (Berntson et al., 1997).

For task periods, all cardiovascular measures obtained during five minutes of task completion were reduced using the same strategy employed for measures obtained during rest. That is, heart rates and blood pressures were each averaged across the five minutes and HRV measures were obtained from spectral analysis of IBIs for the full five-minute period for both the speech and mental arithmetic portions of the task period. Cardiovascular measures during the speech preparation period were not analyzed.

For recovery periods, heart rate (in bpm) was averaged for each minute. For each of the three cortisol measures obtained during recovery periods, the duplicate assays were averaged to obtain a single value. Blood pressure data was not further reduced; that is, each blood pressure value measured in two minute segments was used for the area under the curve analyses. Three separate spectral analyses were conducted on IBIs to obtain measures of HRV during early recovery (mins 0-5), middle recovery (mins 5-10), and late recovery (mins 10-15).

Tests of Statistical Assumptions. Data were examined to ensure the distributions for each variable used in the study approximated normality. There was no evidence for significant skew or kurtosis for distributions of any self-report and physiological data, so no data transformations were conducted. 
Order Effects. Order effects analyses were completed to assess the potential influence of order of task or order of food session. Results revealed no significant order effects.

Area Under the Curve. For each cardiovascular parameter and cortisol during the recovery period, area under the curve (AUC) was calculated to capture rate of recovery for both the No Food Session and the Comfort Food Session. AUC calculations enable one to examine the rate of recovery toward baseline or resting levels. AUC for each variable was calculated using an appropriate version of the following formula:

$$
\begin{aligned}
& \text { AUC }=.50 *(\text { duration of each recovery segment }) *[\text { Recovery } 1+(2 * \text { Recovery } 2+2 * \\
& \text { Recovery } 3 \ldots .2 * \text { Recovery } 14)+ \text { Recovery } 15]- \text { Rest } * \text { Total Recovery Time. }
\end{aligned}
$$

Change Scores and Difference Scores. Next, difference scores between AUC values for the Comfort Food and No Food control sessions were calculated, indicating any difference in rate of recovery during the Food Session and the No Food Session (Food Session value minus No Food Session value). High difference scores indicate a stress enhancement effect of food and low or negative difference scores indicate a stress amelioration effect of food. Additionally, change scores for negative affect and positive affect (as measured by the PANAS) were calculated from the Task Period to the end of the Recovery Period.

Task Reactivity. Prior to addressing study hypotheses regarding recovery from stress, it is important to demonstrate that participants were exposed to tasks that were perceived as stressful. To examine this effect, each measure obtained during the Task Period was contrasted with corresponding measures during the Rest Period using 2 X 2 [Session (Comfort Food, No Food) by Period (Rest, Task)] repeated measures analyses of variance (ANOVAs). Results of 
these analyses revealed that all variables showed a significant change from rest to task except for salivary cortisol (see Table 3 ). Table 2 shows partial correlations between task outcome measures controlling for rest for both sessions.

Analyses of Participant Sex. Because sex of participant has been shown to influence the magnitude of cardiovascular reactivity to mentally stressful tasks like the tasks used in this study (e.g., Whited \& Larkin, 2009), preliminary analyses were conducted comparing task responses and recovery rates of males and females who participated in this study. To examine sex effects on cardiovascular reactivity, a series of 2 X 2 [Sex of Participant (male, female) by Session (Comfort Food, No Food)] mixed factors analyses of covariance (ANCOVAs) were conducted using resting values as covariates. Results revealed no significant sex differences (see Table 4). To examine sex effects on recovery rates, all area under the curve scores were subjected to similar Sex of Participant by Session ANOVAs. Results of these ANOVAs suggest that there were no significant differences between males and females for area under the curve scores (see Table 4). Sex differences on the self-report measures were also examined (emotional, restrained, and binge eating, waist hip ratio, body mass index, depression symptoms, and negative and positive affect change scores), and none showed significant differences based on participant sex $F^{\prime} \mathrm{s}=.001-3.6 ;$ all $\mathrm{ps}>.05$.

Analysis of Influence of Birth Control. Salivary cortisol has been reported to be influenced by hormonal contraceptive use (Kirschbaum \& Hellhammer, 1989). Therefore, before completing analyses, resting cortisol measures for participants who reported currently taking birth control were compared to those who were not taking oral contraceptives. Results of a oneway ANOVA revealed no significant differences in resting cortisol in either the Food or the No 
Food sessions between women who reported using contraceptives $\left(M_{\text {Food }}=.45 \mathrm{ng} / \mathrm{ml}, S D=.16\right.$; $\left.M_{\text {No Food }}=.46 \mathrm{ng} / \mathrm{ml}, S D=.16\right)$, women who did not report using oral contraceptives $\left(M_{\text {Food }}=.50\right.$ $\left.\mathrm{ng} / \mathrm{ml}, S D=.18, M_{\text {No Food }}=.56 \mathrm{ng} / \mathrm{ml}, S D=.22\right)$, and men $\left(M_{\text {Food }}=.49 \mathrm{ng} / \mathrm{ml}, S D=.35, M_{\text {No Food }}\right.$ $=.44 \mathrm{ng} / \mathrm{ml}, S D=.22), p ’ s>.05$.

\section{Hypothesis One: Effect of Comfort Food on Recovery from Stress}

It was hypothesized that recovery from stress would be more immediate when participants consumed a comfort food in comparison to recovering from stress without consuming food. A paired-samples t-test was conducted on all area under the curve values to compare recovery rates during the Food Session with recovery during the No Food session. A paired-samples t-test comparing Food and No Food recovery showed a significant difference in recovery for heart rate, $t(52)=3.72, p<.001$, and systolic blood pressure, $t(48)=2.9, p<.01$. However, comparison of means revealed that these results were opposite of the predicted direction, suggesting that participants showed a slower heart rate and systolic blood pressure recovery during the Food session compared to the No Food session (see Figures 3 and 4). Paired-samples t-tests for other variables showed no significant differences in areas under the curve during the recovery period between the two experimental sessions (see Table 5) ${ }^{1}$.

\section{Hypothesis Two: Relation between Negative Affect and Recovery from Stress}

It was hypothesized that the magnitude of change in negative affect that occurs with food intake following exposure to an acute stress manipulation (i.e., PANAS negative affect change score from rest to end of recovery during Food session) would be associated with a more

\footnotetext{
${ }^{1}$ Analyses excluding men showed the same results.
} 
efficient recovery of the neuroendocrine and autonomic nervous system responses to stress during the Food session compared to the No Food session (i.e., area under the curve difference scores). To test Hypothesis Two, recovery difference scores for both autonomic (HR, BP, HRV) and neuroendocrine (cortisol) parameters were entered into several linear regression analyses with change score for negative affect during the Food session as predictor variable. Results of these linear regression analyses revealed no significant relations between change in negative affect and AUC differences scores for HR, $\beta=.15, t(50)=1.04, p=.31 ; \mathrm{SBP}, \beta=.25, t(51)=$ $1.78, p=.08 ; \mathrm{DBP}, \beta=-.04, t(51)=-.27, p=.79 ; \mathrm{LF} \mathrm{HRV}, \beta=.04, t(51)=.29, p=.77 ; \mathrm{HF}$ $\mathrm{HRV}, \beta=.06, t(51)=.42, p=.67 ;$ and cortisol, $\beta=-.14, t(51)=-.98, p=.33$.

\section{Hypothesis Three: Associations between Measures of Eating Disturbance and Stress}

\section{Recovery Amelioration}

It was hypothesized that several individual difference variables potentially associated with disordered eating would be associated with a more substantial stress amelioration effect of eating comfort foods. The variable thought to be most likely associated with a stress ameliorating effect was emotional eating. To test this hypothesis, difference scores (Food - No Food) for each physiological variable during recovery were regressed on emotional eating scores. Results of these analyses revealed that emotional eating score was a significant predictor of SBP recovery difference score, $\beta=.31, t(47)=2.17, p<.05$, and explained a significant proportion of variance in SBP difference scores, $R^{2}=.09, F(1,46)=4.72, p<.05$. However, the results were opposite of the predicted direction, with higher scores on emotional eating being related to larger difference scores. This suggests that individuals who reported more emotional eating showed prolonged systolic blood pressure recovery upon consuming food in contrast to 
the No Food session. Emotional eating score was not a significant predictor of AUC difference scores for HR, $\beta=.06, t(51)=.42, p=.67$; DBP, $\beta=-.18, t(51)=-1.25, p=.22$; LF HRV, $\beta=$ $.16, t(51)=1.16, p=.25 ; \mathrm{HF} \mathrm{HRV}, \beta=-.07, t(51)=-.48, p=.64$; or cortisol, $\beta=-.10, t(51)=-$ $.68, p=.50$.

It was hypothesized that body mass index, waist hip ratio, depressive symptoms, and symptoms of restrained and binge eating would be negatively related to an abbreviated recovery period in the Food session compared to the No Food session (i.e., larger BMI, WHR, depression, and retrained and binge scores would be associated with lower or negative AUC difference scores). To test this hypothesis, predictor variables (BMI, WHR, CES-D score, DEBQ restrained eating scale, QEWP binge eating score) were entered into a multiple regression analysis, with autonomic and neuroendocrine recovery difference scores as the outcome. Results of multiple regression analyses revealed a significant association between self-reported binge eating and heart rate recovery, $\beta=.40, t(48)=2.23, p<.05$, again opposite of the expected direction. A self-reported history of binge eating was associated with slower heart rate recovery in the Food session compared to the No Food session. All other analyses were not significant and suggest that this hypothesis was not supported (see Tables 6-11).

\section{Exploratory Analysis: Are Parameters associated with Dysfunctional Eating associated with Magnitude of Acute Stress Responding}

Given the overall lack of support for study hypotheses, and evidence from prior work (e.g., Steptoe \& Wardle, 2005) that people with dysfunctional eating habits may experience stress more intensely than those with more healthy eating habits, we conducted exploratory analyses that examined associations between stress reactions using all of the parameters used in 
this study (HR, BP, HRV, and Negative Affect) and the measures of dysfunctional eating obtained on study participants. Because the Food and No Food sessions were virtually identical during the rest and task periods, only data from the first session was used to examine these associations. Partial correlations were calculated between each measure of dysfunctional eating and measures of stress obtained during the task performance, partialing out corresponding resting measures. Results revealed a significant correlation between binge eating and diastolic blood pressure reactivity, $r=-.36, p<.05$, suggesting that participants who reported more emotional eating showed less DBP reactivity to mental stress. These analyses did not reveal any other significant correlations between measures of dysfunctional eating and physiological reactivity (see Table 12).

\section{Discussion}

The present study was designed to test the hypothesis that comfort food attenuates the physiological stress response using a quasi-experimental approach. Study hypotheses were based on the model that emotional eating behaviors were maintained via negative reinforcement, such that those who ate comfort foods following stress experienced a faster recovery of the stress response, and consequently, would be more likely to eat these foods again when exposed to stress. However, the results of the current study do not support this model. Participants did not demonstrate attenuated physiological recovery following consumption of designated comfort foods. In fact, for some physiological parameters, participants showed a longer recovery from stress following consumption of comfort foods than during the No Food Session. Additionally, we hypothesized that participants who exhibited risk factors associated with obesity and disordered eating would demonstrate a more rapid stress recovery upon consuming comfort 
foods; however, results did not support a positive relation between these risk factors and stress amelioration. Again, the only significant results observed were in the opposite of the predicted direction.

Reactivity to Mental Stress. In order to test study hypotheses, it was necessary to examine whether physiologic measures of reactivity to stress were observed. Reactivity to stress, as measured from rest to task periods, during the experimental sessions was demonstrated for all cardiovascular variables, as predicted. However, salivary cortisol did not demonstrate increases from the rest period to the first measure of cortisol during the recovery period within the experimental sessions. Given that the stress tasks used in the present study have, historically, been associated with increased cortisol response, it is surprising that reactivity in this parameter was not noted. It is unlikely that participants did not show any cortisol response to the Trier Social Stress Test. It is more likely that the saliva measures taken in the present study were too close to the time of the stress, such that measurements were taken before the height of the cortisol response. A longer recovery period would enable more time to lapse between the stressor and cortisol measurements, which may have more accurately reflected the recovery curve following presentation of the stressor and food intake. Cortisol release occurs more distally in the physiological stress response, thus occurring at a delayed stage in the stress response sequence compared to autonomic responses such as heart rate and blood pressure. Given this lack of cortisol reactivity, it is unclear whether the null hypothesis is supported regarding cortisol or if results would differ had significant changes in cortisol been observed in response to mental stress. 
Effect of Comfort Food on Recovery from Stress. Hypothesis One stated that recovery from stress would be more immediate when participants consumed a comfort food in comparison to recovering from stress without consuming food. Analyses showed effects in the opposite of the expected direction for both heart rate and systolic blood pressure, but no significant effects were observed among the other physiological variables. There are several potential explanations for these results. First, the laboratory environment is markedly different from the environment in which participants typically eat food following exposure to stress. Though the room was physically comfortable (a comfortable chair, with temperature and lighting adjusted as requested), the laboratory environment is very different from someone's kitchen table, a comfortable couch, or a favorite restaurant. If the stress amelioration phenomenon occurs, it may require a context similar to the natural environment in which comfort foods are normally consumed. In this regard, the experimental environment did not create an externally valid context that enabled participants to experience the types of stress-ameliorating effects they might exhibit in daily life.

The phenomenon may only be observed in the specific environment in which the stresseating typically occurs (e.g., the living room). In this regard, the current study failed to expose participants to the conditioned place preference associated with their comfort eating. Comfort food eating may be similar to the effects observed among those with drug dependence problems (e.g., Davis \& Carter, 2009). Conditioned place preference is a well-known phenomena in which a previously neutral set of environmental stimuli (unconditioned stimuli) are consistently paired with a drug administration such that they elicit approach behaviors and become conditioned stimuli for the drug effects (including drug tolerance). For example, if a mouse or rat is placed in a chamber with black and white stripes, and the drug is only administered in the striped chamber, 
the animal seeks out the striped chamber and shows more effects of the drug when it is administered in this environment. When the drug is administered in other environments, differential drug effects are observed. Results of the continuous pairing of a specific environment with the drug administration show that subjects are more likely to seek out the conditioned environment and the actual drug effects may be enhanced in the conditioned environment (Tzschentke, 2007).

A conditioned environment effect could also be observed for consuming comfort foods and experiencing stress-amelioration, especially as certain foods have been observed to have similar neurochemical effects as "addictive" drugs. Specifically neuropeptides found in sugar and fat may elevate mood and result in cravings similar to those seen in drug dependence (Davis \& Carter, 2009). Therefore, it may be logical to apply this conditioned place preference model to comfort food intake following stress. It is possible that those individuals who consume a "comforting" food following stress typically do so in a certain environment (e.g., the blue sofa in the sitting room while watching TV alone). Within the context of this environment, the person may experience a stress-ameliorating effect, thus negatively reinforcing consumption of the comfort food. However, outside of this environment, the effects may be less apparent, especially while being observed in an unfamiliar laboratory environment.

Additionally, several of the hypotheses in the present study were based on research done with animals exposed to chronic stress. For example, in the study by Pecoraro and colleagues (2004), rats were chronically stressed with a restraint technique, and the experimental group was given a sugar and lard mixture over the course of several days. Results at the end of the study showed that those who were stressed but ate the "comfort food" had a less dramatic 
corticosterone response. Though results before the end of this study were trending toward this stress-reduction effect, they were not evident early in the study. It is possible that the stress amelioration effect hypothesized in the current study would become evident if participants were exposed to the stress-food pairing over the course of multiple days. The results of the studies by Fachin and colleages (2008) and Ulrich-Lai and colleagues (2007) also lend support toward the more prolonged development of a stress-amelioration effect. In these studies, eating following stress resulted in a smaller adrenal gland weight (Fachin et al., 2008) and a change in the thymus and adrenals (Ulrich-Lai et al., 2007), a process that would take an extended period of time. In the current study, where participants were exposed to stress for ten minutes on two occasions one week apart, there may not have been enough time for the stress-reducing effects of the comfort food to have been conditioned.

Participant food choice may be an additional factor in understanding why study results were contrary to study hypotheses and observations from the previous literature. As mentioned above, the literature suggests some form of reduced stress response or recovery amelioration occurs upon consumption of foods high in sugar and/or fat, often comparing this type of food to a "typical diet” [e.g., "chow" versus a lard/sugar combination (Pecoraro et al., 2004); carbohydrate rich/protein poor diet versus carbohydrate poor/protein rich diet (Markus, 2000; 2007)]. In the present study, participants were permitted to choose the food they would eat, resulting in a wide variety of food choices (see Table 13). Participants were asked to indicate a food they would describe as a "comfort food," and instructed to be as specific as possible in the description (including brand, flavor, etc). This was done to increase the external validity of the experiment, since research suggests that there is a large variety among the population's preferred comfort foods. For example, men tend to prefer warm and hearty foods whereas women prefer 
snack-like foods (Wansink, Cheney, \& Chan, 2003). Food choices for the current study varied greatly among participants, including things as vastly different as Doritos, noodles, brownies, chocolate, macaroni and cheese, potatoes, rice, ice cream, soup, pizza, fruit, and yogurt. Though some of these foods might fit into the more "stereotypical" definition of high fat, high sugar comfort foods, others are less likely to fit into that category. If stress amelioration effects are associated with consuming just high-fat or high-sugar foods, it would not be surprising no effects were observed in this study where participants did not consistently select foods of this type. The variation among foods selected by study participants may be associated with the divergence of the present results from the predicted outcome.

It is interesting to note that both heart rate and systolic blood pressure took significantly longer to recover following comfort food consumption. It may be the case that participants were simply moving more while eating, and were not moving during the corresponding time of the recovery in the No Food session. Participant movement may have influenced both blood pressure and heart rate. Additionally, examination of the literature on autonomic response to food ingestion suggests that this may be consistent with the typical patterning of post-meal physiological responses. Specifically, research into the physiology of digestion suggests that heart rate and blood pressure either remain constant or increase following food intake (Lipsitz, Ryan, Parker, Freeman, Wei, \& Goldberger, 1993). In contrast, some elderly individuals demonstrate a decrease in blood pressure following a meal, called "postprandial hypotension," and it is associated with increased risk for syncope and falling. The following mechanisms have been proposed to explain post-prandial hypotension: “1) age- or hypertension-related impairments in baroreflex function, 2) insulin-induced vasodilation or baroreflex impairment, 3) release of vasodilatory gastrointenstinal peptides, 4) excessive...blood pooling during digestion, 
and 5) inadequate sympathetic nervous system compensation for meal ingestion" (p. 392; Lipsitz et al., 1993). Given the age-related determinants associated with this condition, it is unlikely that the population of individuals who participated in this study would have demonstrated reductions in heart rate or blood pressure after eating, as this would be contrary to a typical healthy physiological reaction of young adults.

Though no significant heart rate variability results were reported in the present study, recent research into the heart rate variability response to eating suggests that HRV may, in fact increase, following ingestion of foods high in calories or carbohydrates (Kuwahara, Okita, Kouda, \& Nakamura, 2011). One study of young Japanese men exposed participants to one of three conditions: a fasting condition, a high-calorie/high-fat meal, or a moderate-calorie/highcarbohydrate meal. Heart rate and heart rate variability data were gathered 30, 60, 90, and 120 minutes after meal intake. Generally, results indicated decreased sympathetic modulation and increased parasympathetic modulation (increased high frequency heart rate variability) of the heart following the fasting condition. However, the opposite results were reported following either of the "modern" diets: participants eating fat or carbohydrates showed increased heart rate and decreased high frequency power during recovery, indicating either onset of sympathetic reaction or parasympathetic withdrawal (Kuwahara et al., 2011). This recent research suggests that, though heart rate variability is influenced by eating, that it again would likely not demonstrate an expedited recovery. In contrast to study hypotheses, findings from the current study conform to this recent evidence suggesting that eating is associated with increased rather than decreased physiological arousal. 
Relation between Negative Affect and Recovery from Stress. Hypothesis Two stated that the magnitude of change in negative affect that occurs with food intake following exposure to an acute stress manipulation (i.e., PANAS negative affect change score from rest to end of recovery during Food session) would be associated with a more efficient recovery of the neuroendocrine and autonomic nervous system responses to stress during the Food session compared to the No Food session (i.e., area under the curve difference scores). This hypothesis was not supported for any outcome variable. These results may be influenced by the lack of any demonstrated physiological stress reduction effect associated with food intake (discussed above). Additionally, one of the founding premises of this hypothesis was that many people would report either reductions in negative affect or increases in positive affect following comfort food intake immediately after stress (e.g., Dubé, LeBel, \& Lu, 2005). One potential reason for the lack of support for this hypothesis might be that this change in affect was not observed in the present study. To test this idea, a paired-samples t-test was used to compare Food and No Food sessions for change in affect from stress to the end of recovery (affect change score). Results showed no significant difference between sessions for positive affect or negative affect change scores during the recovery period (see Table 5). Thus, it is reasonable to conclude that one reason this hypothesis was not supported was due to the fact that insufficient change in affect occurred.

Associations between Eating Disturbance and Stress Recovery Amelioration. Hypothesis Three stated that several individual difference variables associated with disordered eating would be related to a more substantial stress amelioration effect of eating comfort foods, with emotional eating being a particular variable of interest. Additionally, it was hypothesized that body mass index, waist hip ratio, depressive symptoms, and symptoms of restrained and binge eating would be related to a more rapid recovery from stress in the Food session compared to the No Food 
session. Results showed a significant association between self-reported emotional eating as well as binge eating and heart rate recovery, but in the opposite direction. Specifically, participants who reported more symptoms of emotional eating and binge eating were more likely to take a longer time to recover physiologically following stress when they ate a favorite comfort food compared to when they did not (SBP for emotional eating and HR for binge eating). Although not hypothesized, this result is logical, given the typical psychopathology of binge eating. Participants who reported higher scores on the measure of binge eating endorsed items such as eating an "unusual amount of food" within a two-hour period, feeling out of control of their eating, and being upset by their eating more than participants with lower scores. With such a history, these individuals may experience increased anxiety and shame when they consumed a comfort food while being observed in a laboratory. In fact, there is some evidence that people who binge exhibit greater physiological responses following food ingestion than non-binging controls (e.g., Vögele \& Florin, 1997). Food, particularly comfort food, for these patients is viewed in much the same way as a snake phobic patient views a garden snake; increased arousal is expected upon food consumption than a relaxing effect. Additionally, patients with binge eating disorder have been found to have more comorbid psychopathology, with depression, social anxiety, and self-consciousness being significantly associated with frequency of binges (Sawaoka, Barnes, Blomquist, Masheb, \& Grilo, 2011). In this regard, it is not really surprising that participants with higher scores on this measure, although not diagnosed with bulimia, tend to view food consumption as more anxiety-evoking than those with lower scores.

\section{Association between Dysfunctional Eating and Acute Stress Responding. Participants} who reported more emotional eating in the past showed slower recovery when they ate compared to a No Food session. The literature suggests that those with binge eating, and perhaps emotional 
eating, may show more reactivity to stress (Vögele \& Florin, 1997). To test the possibility that those who experience dysfunctional eating symptoms may show differences in physiologic reactivity to stress, we conducted partial correlations between physiological measures of stress reactivity and measures of dysfunctional eating. Results did not demonstrate more reactivity for people reporting more eating pathology; in fact, the only significant relation to be observed showed that participants who were more likely to binge eat had less diastolic blood pressure reactivity to mental stress. It is unclear why this result occurred, especially given that other studies have demonstrated increased blood pressure effects among people who binge, especially when exposed to a binge food (Vögele \& Florin, 1997). Perhaps because the stressor in the present study was unrelated to food, people who binge did not show increased physiologic response compared to others. However, because this finding was derived from an exploratory analysis of data and there was no correction made for calculating multiple correlation coefficients, it is possible that the finding is a statistical artifact. Future research is needed to bear this out.

\section{Limitations of this Study}

The following limitations should be taken into consideration when interpreting the results of the present study. First, this study was conducted within a laboratory environment. Though the Trier Social Stress Test has been shown to produce autonomic and neuroendocrine responses to stress in the lab that mirror the same types of responses seen in daily life, it is possible that a stress amelioration effect could not be detected in a laboratory environment. In particular, if stress amelioration associated with comfort food consumption can be conditioned to environmental context, as discussed above, conducting a study like this in a laboratory instead of 
a real-life environment represents a significant limitation. Additionally, in a stressful situation outside of the lab, participants would likely have unlimited time to consume as much of a desired food as they wanted to at the time. The present study limited the time period to five minutes, and participants were given a set amount of the food (i.e., they did not "binge"). A similar study, in which participants are subjected to interpersonal stress and then allowed to binge, may be more revealing regarding the effects of binging specifically. The study is also limited in that a "healthy food" condition was not included, which would have allowed comparisons of recovery from stress while eating comfort food, recovery from stress while eating non-comfort food, and no food.

Next, the study is limited by the length of the recovery period employed. The present study utilized a 15 minute recovery period, which has been used for some studies of physiological recovery. However, other studies have utilized longer recovery periods (e.g., 30120 minutes, Kuwahara et al., 2011). A longer recovery time could have helped to clarify the influence of consumption of food on recovery. In particular, because the recovery period also included a five min eating phase during the Food Session, it may have been beneficial to extend the recovery phase several minutes longer, or even double its length, in order to disentangle the physiological effects of eating from the physiological recovery from stress. Additionally, a longer recovery period would have enabled more time to lapse between cortisol measurements, which may have more accurately reflected the recovery curve following presentation of the stressor and food intake. Cortisol release occurs more distally in the physiological stress response, thus occurring at a delayed stage in the stress response sequence compared to autonomic responses such as heart rate and blood pressure. Related to the cortisol analyses, the present study is limited by the inability to control for time in the menstrual cycle for women 
participants. Though participants were queried as to the date of last menses, some participants were not sure of this information and some data were missing, so there was not enough data to analyze for differences in menstrual cycle phase. The available data show, however, that levels of cortisol were not different between men and women or between women who take contraceptives and those who do not. Finally, the present study was comprised primarily of young college students; therefore, results may not be generalizable to other populations.

\section{Future Directions and Conclusions}

Findings from this study have implications for both future research and clinical applications. Future research could benefit from testing the effects of comfort food on physiological recovery from stress outside of the lab. The present results showed that, within the laboratory, comfort food did not speed physiological recovery following exposure to stress. However, it may be the case that these stress amelioration effects are conditioned phenomena and only occur outside of the laboratory. Therefore, future studies using ambulatory physiological recording instruments in natural settings would be one way to examine this empirical question. Further research into the predictors of specific food choices could also clarify the relation between stress and comfort food intake. Some participants in the present study chose to eat foods high in fat, sugar, or carbohydrates, whereas others did not. Unfortunately, there were not enough participants selecting the same types of foods in the current study for a proper consideration of this question using the current data. Examining the predictors of food choice could help to clarify the risk factors for unhealthful eating patterns and contribute to interventions. It is possible that there are other individual difference variables that moderate stress amelioration effects (e.g., availability of social support, repertoire of coping 
skills, current stressful events in participants' lives); further research into these potential moderators may clarify the existence of the effect in humans.

The lack of support for a negative reinforcement model in the present study may have relevance clinically. Because the present results do not support a negative reinforcement model, any clinical intervention for eliminating over-consumption of comfort foods would likely be less effective if based upon this model. For example, if the negative reinforcement hypothesis were supported, interventions geared toward replicating the physiologic effects of comfort food eating could be devised and tested among patients with problems associated with overeating comfort foods (e.g., relaxation in order to reduce physiological arousal following stress). Though these interventions would likely be helpful to improve coping mechanisms, it appears that simply removal of unpleasant physical stimuli would not replace any reliance on comfort food. It is also possible that binging behavior or frequent consumption of comfort foods is maintained through positive rather than negative reinforcement [e.g., through neuropeptides found in high fat and carbohydrate foods (Davis \& Carter, 2009) or improved affect]. If this were experimentally confirmed, this suggests that patients with eating problems would respond better to replacing the binging behavior with another behavior that would have a similar appetitive effect.

If the present findings are replicated, and physiological comfort actually does not result from eating "comfort" foods following stress, this fact may prove to be clinically useful. The term "comfort food," as used in lay conversation, implies that certain foods exist that will make one "feel better;" they are meant for use following a difficult or stressful time as a way to solve the problem. However, it may be the case that we are getting the wrong message about these foods. Tobacco products have been described by their users as being relaxing; however, 
physiological data show that nicotine causes vasoconstriction and increased blood pressure, the physiological opposites of relaxation. Informing consumers of tobacco that they are not relaxing by using consuming it is one way to lead them toward quitting. Perhaps informing people that they are not, in fact, comforting themselves by eating that candy bar or extra plate of mac and cheese would be one step toward clinical intervention.

As is the case with other psychopathology, the most effective approach to binge eating is likely from an idiographic functional analytic perspective. For example, if a client reports binge eating following work when she is tired, immediately before bed, and when alone, determining the function of the binging behavior for that individual would likely lead to the most promising clinical outcomes. In this particular case, the patient might state that she engaged in binge eating 1) when she felt pressed for time and did not have other meals prepared, so it alleviated stress of preparing a meal, 2) when she wanted to feel relaxed and indulgent before bed, and 3) when she was lonely, to improve negative affect associated with being alone. When working with a patient like this, it would make sense to find activities that provide the desired effect (e.g., planning meals in advance, taking a bath, calling a friend) that would eliminate stress and loneliness so that binging would no longer be the only route to obtaining these outcomes. Interventions geared toward similar idiographic functional assessment and skills training [e.g. Cognitive behavioral therapy for eating disorders (CBT-E; Fairburn, Cooper, \& Shafran, 2008)], as well as interventions designed to teach improved negative affect tolerance [e.g., Dialectical Behavioral Therapy for Binge Eating Disorder (DBT-BED; Safer, Robinson, \& Jo, 2010)] and present moment awareness (e.g., Mindfulness Based Eating Awareness Therapy) utilize positive reinforcement approaches (see Wilson, 2011 for a review of recent treatments for binge eating) and could be quite useful for patients who over-consume comfort foods. 
In summary, the hypothesis that comfort food consumption is maintained by negative reinforcement through the enhanced withdrawal of unpleasant physiological stress responding was not supported. It is unclear at this point why some results reported in animal research do not translate into similar findings with humans. Certainly, the cognitive-verbal abilities of humans should be examined to determine what role they may play in influencing conditioned food consumption responses that differ between animals and humans. However, given that the present findings are discrepant from those reported in small mammal literature, future research is needed to investigate the variation in this effect for humans. By doing so, we may comprehend why so many humans become entangled in patterns of dysfunctional eating that place them at great risk for living less healthy and far shorter lives. 


\section{References}

Apovian, C. M. (2009). The causes, prevalence, and treatment of obesity revisited in 2009: What have we learned so far? American Journal of Clinical Nutrition, 91, 277S-279S.

Borenstein, Rothstein, Cohen, Schoenfield, \& Berlin (2000). Sample Power (Version 2) [Computer Software]. SPSS, Inc.

Brinkworth, G. D., Noakes, M., Buckley, J. D., \& Clifton, P. M. (2006). Weight loss improves heart rate recovery in overweight and obese men with features of the metabolic syndrome. American Heart Journal, 152, 693.e1-693.e6.

Brosschot, J. F. \& Thayer, J. F. (1998). Anger inhibition, cardiovascular recovery, and vagal function: A model of the link between hostility and cardiovascular disease. Annals of Behavioral Medicine, 20, 326-332.

Buwalda, B., Blom, W. A. M., Koolhaas, J. M., \& van Dijk, G. (2001). Behavioral and physiological responses to stress are affected by high-fat feeding in male rats. Physiology \& Behavior, 73, 371-377.

Centers for Disease Control: National Center for Health Statistics (2007). Health, United States, 2007 with chartbook on trends in the health of Americans. Hyattsville, MD.

Crothers, L. M., Kehle, T. J., Bray, M. A., \& Theodore, L. A. (2009). Correlates and suspected causes of obesity in children. Psychology in the Schools, 46, 787-796. doi:

10.1002/pits.20417 
D’Angelo, G., Mintz, J. D., Tidwell, J. E., Schreihofer, A. M., Pollock, D. M., \& Stepp, D. W. (2006). Exaggerated cardiovascular stress responses and impaired $\beta$-adrenergic-mediated pressor recovery in Obese Zucker rats. Hypertension, 48, 1109-1115.

Dallman, M. F., Pecoraro, N. C., \& la Fleur, S. E. (2005). Chronic stress and comfort foods: Self-medication and abdominal obesity. Brain, Behavior, \& Immunity, 19, 275-280.

Davis, C. \& Carter, J. C. (2009). Compulsive overeating as an addiction disorder. A review of theory and evidence. Appetite, 53, 1-8. doi:10.1016/j.appet.2009.05.018

Epel E., Lapidus, R. , McEwen, B., \& Brownell, K. (2001). Stress may add bite to appetite in women: A laboratory study of stress-induced cortisol and eating behavior. Psychoneuroendocrinology, 26, 37-49.

Fachin, A., Silva, R. K. S., Noschang, C. G., Pettenuzzo, L., Bertinetti, L., Billdore, M. N., et al. (2008). Stress effects on rats chronically receiving a highly palatable diet are sex-specific. Appetite, 51, 592-598.

Fairburn, C. G., Cooper, Z., \& Shafran, R. (2008). Enhanced cognitive behavior therapy for eating disorders ('CBT-E'): An overview. In Fairburn, C. G. (Ed.), Cognitive behavior therapy and eating disorders (23-34). New York, NY: Guilford Press.

Faul, F., Erdfelder, E., Lang, A. G., \& Buchner, A. (2007). G*Power 3: A flexible statistical power analysis program for the social, behavioral, and biomedical sciences. Behavior Research Methods, 39, 175-191.

Furukawa, S., Fujita, T., Shimabukuro, M., Iwaki, M., Yamada, Y., Nakajima, Y., 
et al. (2004). Increased oxidative stress in obesity and its impact on metabolic syndrome. The Journal of Clinical Investigation, 114, 1752-1761.

Giacosa, A., Franceschi, S., La Vecchia, C., Favero, A., \& Andreatta, R. (1999). Energy intake, overweight, physical exercise, and colorectal cancer. European Journal of Cancer Prevention, 8, 53-60.

Gianaros, P. J., Sheu, L. K., Matthews, K. A., Jennings, J. R., Manuck, S. B., \& Hariri, A. R. (2008). Individual differences in stressor-evoked blood pressure reactivity vary with activation, volume, and functional connectivity of the amygdale. The Journal of Neuroscience, 28, 990-999.

Gibson, E. L. (2006). Emotional influences on food choice: Sensory, physiological and psychological pathways. Physiology \& Behavior, 89, 53-61.

Goodie, J. L., Larkin, K. T., \& Schauss, S. L. (2000). Validation of the Polar heart rate monitor for assessing heart rate during physical and mental stressors. Journal of Psychophysiology, 14, 159-164.

Greeno, C. G. \& Wing, R. R. (1994). Stress-induced eating. Psychological Bulletin, 115, 444464.

Grunberg, N. E. (1982). The effects of nicotine and cigarette-smoking on food consumption and taste preferences. Addictive Behaviors, 7, 317-331.

Grunberg, N. E., \& Straub, R. O. (1992). The role of gender and taste class in the effects of stress on eating. Health Psychology, 11, 97-100. 
Harthoorn, L. F. \& Dransfield, E. (2008). Periprandial changes of the sympatheticparasympathetic balance related to perceived satiety in humans. European Journal of Applied Physiology, 102, 601-608.

Hellhammer, J. \& Schubert, M. (2012). The physiological response to Trier Social Stress Test related to subjective measures of stress during but not before or after the test. Psychoneuroendocrinology, 37, 119-124. doi:10.1016/j.psyneuen.2011.05.012

Heponiemi, T., Elovainio, M., Pulkki, L., Puttonen S., Raitakari, O., Keltikangas-Jarvinen, L., \& (2007). Cardiac autonomic reactivity and recovery in predicting carotid atherosclerosis: The Cardiovascular Risk in Young Finns Study. Health Psychology, 26, 13-21.

Kinzig, K. P., Hargrave S. L., \& Honors, M. A. (2008). Binge-type eating attenuates corticosterone and hypophagic responses to restraint stress. Physiology \& Behavior, 95, 108-113.

Kirschbaum, C., \& Hellhammer, D. H. (1989). Salivary cortisol in psychobiological research: An overview. Neuropsychobiology, 22, 150-169.

Kirschbaum, C., Wust, S., Hellhammer, D.H. (1992). Consistent sex differences in cortisol reponses to psychological stress. Psychosomatic Medicine, 54, 648-657.

Kirschbaum, C., Pirke, K.-M., \& Hellhammer, D. H. (1993). The 'Trier Social Stress Test:' A tool for investigating psychobiological stress responses in a laboratory setting. Neuropsychobiology, 28, 76-81. 
Klein, L. C., Faraday M. M., Quigley, K. S., \& Grunberg, N. E. (2004). Gender differences in biobehavioral aftereffects of stress on eating, frustration, and cardiovascular responses. Journal of Applied Social Psychology, 24, 538-562.

Koebnick, C., Smith, N., Huang, K., Martinez, M., Clancy, H., \& Kushi, L. (2012). The prevalence of obesity and obesity-related health conditions in a large, multiethnic cohort of young adults in California. Annals of Epidemiology, 22, 609-616. doi:10.1016/j.annepidem.2012.05.006.

Laederach-Hoffman, K., Mussgay, L., \& Ruddel, H. (2000). Autonomic cardiovascular regulation in obesity. Journal of Endocrinology, 164, 59-66.

La Fleur, S. E. (2006). The effects of glucocorticoids on feeding behavior in rats. Physiology \& Behavior, 89, 110-114.

Lubin, B., van Whitlock, R., Reddy, D., \& Petren, S. (2001). A comparison of the short and long forms of the Multiple Affect Adjective Checklist-Revised (MAACL-R). Journal of Clinical Psychology, 57, 411-416.

Markus, C. R. (2007). Effects of carbohydrates on brain tryptophan availability and stress performance. Biological Psychology, 76, 83-90.

Markus, R., Panhuysen, G., Tuiten, A., \& Koppeschaar, H. (2000) Effects of food on cortisol and mood in vulnerable subjects under controllable and uncontrollable stress. Physiology \& Behavior, 70, 333-342. 
Markus, R., Panhuysen, G., Tuiten, A., Koppeschaar, H., Fekkes, D., \& Peters, M. L. (1998). Does carbohydrate-rich, protein-poor food prevent a deterioration of mood and cognitive performance of stress-prone subjects with subjected to a stressful task? Appetite, 31, 4965.

Matthews, K. A., Stoney, C. M., McCann, B. S., \& Manuck, S. B. (1986). Sex and adult child differences in blood-pressure responses to behavioral stress. Psychosomatic Medicine, 48, 302.

Nangle, D. W., Johnson, W. G., Carr-Nangle, R. E. \& Engler, L. B. (1994). Binge eating disorder and the proposed DSM-IV criteria: Psychometric analysis of the questionnaire of eating and weight patterns. International Journal of Eating Disorders, 16, 147-157.

National Institutes of Health. (1998). Clinical guidelines on the identification, evaluation, and treatment of overweight and obesity in adults: The evidence report. Retrieved November 9, 2008, from, www.nhlbi.nih.gov/guidelines/obesity/ob_gdlns.htm.

Neumark-Sztainer, D., Wall, M., Larson, N., Eisenberg, M., \& Loth, K. (2011). Dieting and disordered eating behaviors from adolescence to young adulthood: Findings from a 10year longitudinal study. Journal of the American Dietetic Association, 111, 1004-1011. doi: 10.1016/j.jada.2011.04.012

Niskanen, J., Tarvainen, M. P., Ranta-aho, P. O., \& Karjalainen, P. A. (2002). Software for advances HRV analysis. Submitted to Computer Methods and Programs in Biomedicine.

Pasquali, R., Anconetani, B., Chattat, R., Biscotti, M., Spinucci, G., Casimirri, F., et al. (1996). Hypothalamic-pituitary-adrenal axis activity and its relationship to the autonomic 
nervous system in women with visceral and subcutaneous obesity: Effects of the corticotropin-releasing factor arginine-vasopressin test and of stress. Metabolism: Clinical and Experimental, 45, 351-356.

Pecoraro N., Reyes F., Gomez F., Bhargava A., \& Dallman M. F. (2004). Chronic stress promotes palatable feeding, which reduces signs of stress: feedforward and feedback effects of chronic stress. Endocrinology, 145, 3754-62.

Porges, S. W. (1995). Cardiac vagal tone: A physiological index of stress. Neuroscience and Biobehavioral Reviews, 19, 225-233.

Radloff, L. S. (1977). The CES-D Scale: A self-report depression scale for research in the general population. Applied Psychological Measurement, 1, 385-401.

Rosmond, R., Dallman, M. F., \& Bjorntorp, P. (1998). Stress-related cortisol secretion in men: Relationships with obesity and endocrine, metabolic, and hemodynamic abnormalities. Journal of Clinical Endocrinology \& Metabolism, 83, 1853-1859.

Rowland, N. E. \& Antelman, S. M. (1976). Stress-induced hyperphagia and obesity in rats: A possible model for understanding human obesity. Science, 191, 310-312.

Safer, D. L., Robinson, A. H., \& Jo, B. (2010). Outcome from a randomized controlled trial of group therapy for binge eating disorder: Comparing dialectical behavior therapy adapted for binge eating to an active comparison group therapy. Behavior Therapy, 41, 106-120. doi: 10.1016/j.beth.2009.01.006 
Sawaoka, T., Barnes, R. D., Blomquist, K K., Masheb, R. M., \& Grilo, C. M. (2011). Social anxiety and self-consciousness in binge eating disorder: associations with eating disorder psychopathology. Comprehensive Psychiatry, 53, 740-745. doi:

10.1016/j.comppsych.2011.10.003

Sedova, L., Berube, J., Gaudet, D., Dumont, M., Tremblay, J., Hamet, P. et al. (2004). Dietinduced obesity delays cardiovascular recovery from stress in spontaneously hypertensive rats. Obesity Research, 12, 1951-1958.

Shean, G. \& Baldwin, G. (2008). Sensitivity and specificity of depression questionnaires in college-age sample. The Journal of Genetic Psychology: Research and theory on human development, 169, 281-288. Doi: 10.3200/GNTP.169.3.281-292

Shepard, V. E. (2006). The obesity epidemic: Its causes and methods of assessment. Practice Nurse, 31, 41-45.

Spitzer, R. L., Devlin, M., Walsh, B. T., Hasin, D., Wing, R., Marcus, M., et al. (1992). Binge Eating Disorder: A multisite field trial of the diagnostic criteria. International Journal of Eating Disorders, 11, 191-203.

Steptoe, A., \& Wardle, J. (2005). Cardiovascular stress responsivity, body mass index and abdominal adiposity. International Journal of Obesity, 29, 1329-1337.

Telch, C. F., \& Agras, W.S. (1996). Do emotional states influence binge eating in the obese? International Journal of Eating Disorders, 3, 271-279. 
Tuschen-Caffier, B., \& Vogele, C. (1999). Psychological and physiological reactivity to stress: An experimental study on bulimic patients, restrained eaters and controls. Psychotherapie Psychosomatic, 68, 333-340.

Tsuji, H., Venditti, F. J., Manders, E. S., Evans, J. C., Larson, M. G., Feldman, C. L. et al. (1994). Reduced heart rate variability and mortality risk in an elderly cohort: The Framingham Heart Study. Circulation, 90, 878-883.

Tzschentke, T. M. (2007). Measuring reward with the conditioned place preference (CPP) paradigm: update of the last decade. Addiction Biology, 12, 227-462. doi:10.1111/j.13691600.2007.00070.x

Ulrich-Lai, Y. M., \& Herman, J. P. (2009). Neural regulation of endocrine and autonomic stress responses. Nature Reviews: Neuroscience, 10, 397-409.

Valensi, P., Phan Thi, B. N., Lormeau, B., Paries, J., \& Attali, J. R. (1995). Cardiac autonomic function in obese patients. International Journal of Obesity, 19, 113-118.

van Strien, T., Frijters, J. E. R., Bergers, G. P. A., \& Defares, P. B. (1986). The Dutch Eating Behavior Questionnaire (DEBQ) for assessment of restrained, emotional, and external eating behavior. International Journal of Eating Disorders, 5, 295-315.

Vigo, D. E., Castro, M. N., Dorpinghaus, A., Weidema, H., Cardinali, D. P., Siri, L. N., et al. (2008). Nonlinear analysis of heart rate variability in patients with eating disorders. The World Journal of Biological Psychiatry, 9, 183-189. 
Vögele, C. \& Florin, I. (1997). Physiological responses to food exposure: An experimental study in binge eaters. International Journal of Eating Disorders, 21, 147-157.

Wansink, B., Cheney, M. M., \& Chan, N. (2003). Exploring comfort food preferences across age and gender. Physiology \& Behavior, 79, 739-747. doi:10.1016/S0031-9384(03)00203-8

Watson, D., Clark, L. A., \& Tellegen, A. (1988). Development and validation of brief measures of positive and negative affect: The PANAS scales. Journal of Personality and Social Psychology, 54, 1063-1070. 10.1037/0022-3514.54.6.1063

Whited, M. C., \& Larkin, K. T. (2009). Sex differences in cardiovascular reactivity: Influence of the gender role relevance of social tasks. Journal of Psychophysiology, 23, 77-84.

Yamamoto, K., Shimokawa, T., Yi, H., Isobe, K., Komija, T., Loskutoff, D. J. et al. (2002). Aging and obesity augment the stress-induced expression of tissue factor gene in the mouse. Blood, 100, 4011-4018. doi: 10.1182/blood-2002-03-0945 


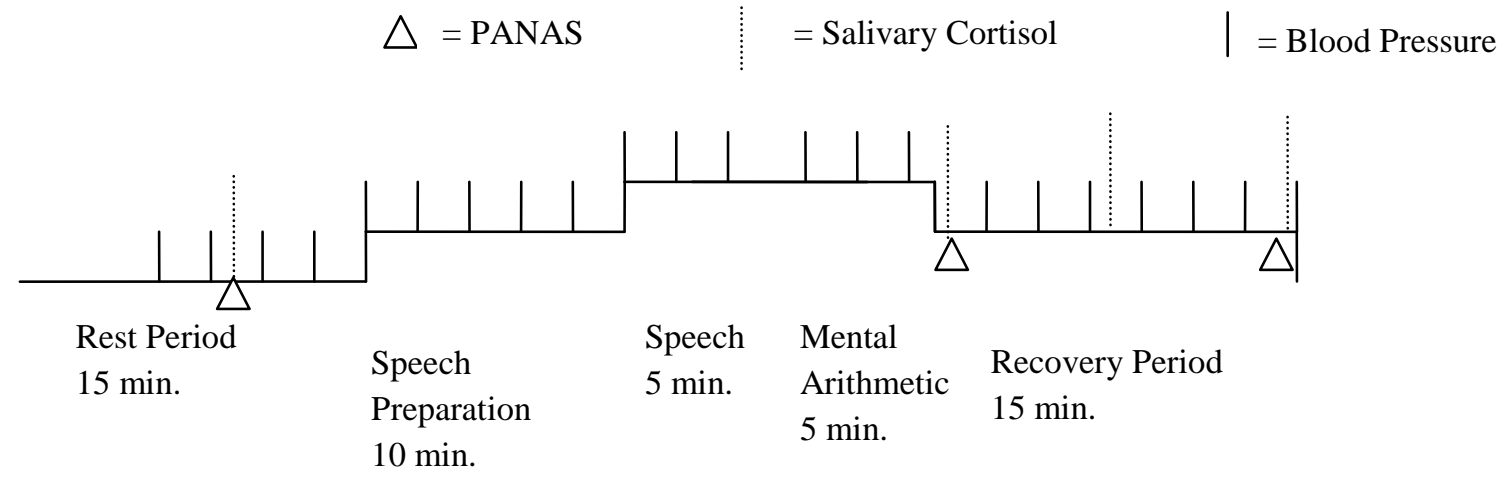

Figure 1. No Food Session procedure. 


$$
\triangle \text { = PANAS } \quad \quad \quad=\text { Salivary Cortisol } \quad \mid=\text { Blood Pressure }
$$

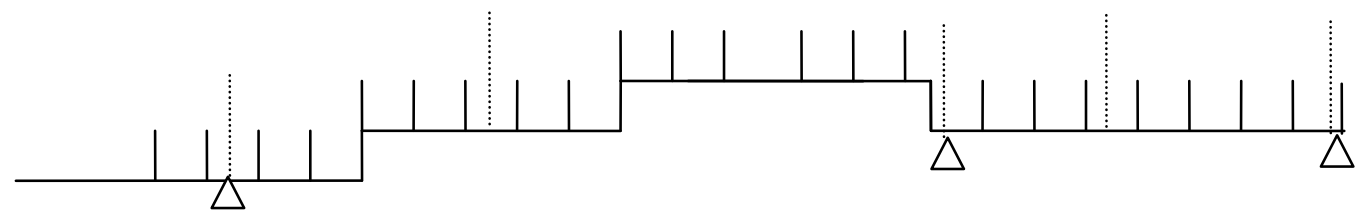

Rest Period

Speech

Preparation

10 min.

Speech Mental

$5 \mathrm{~min}$.

Arithmetic

5 min.
Recovery Period

15 min.

Food Minutes 2-7

Figure 2. Food Session procedure. 


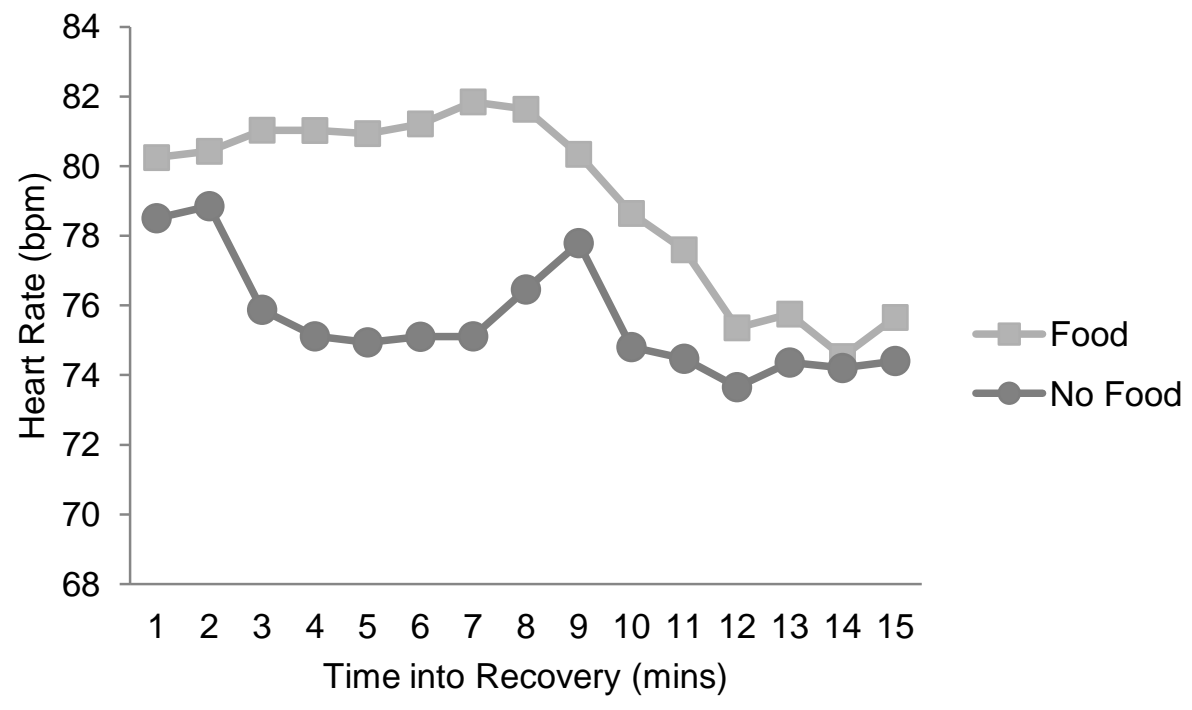

Figure 3. A visualization of heart rate recovery during Food and No Food sessions; recovery occurred significantly more quickly in the No Food session. 


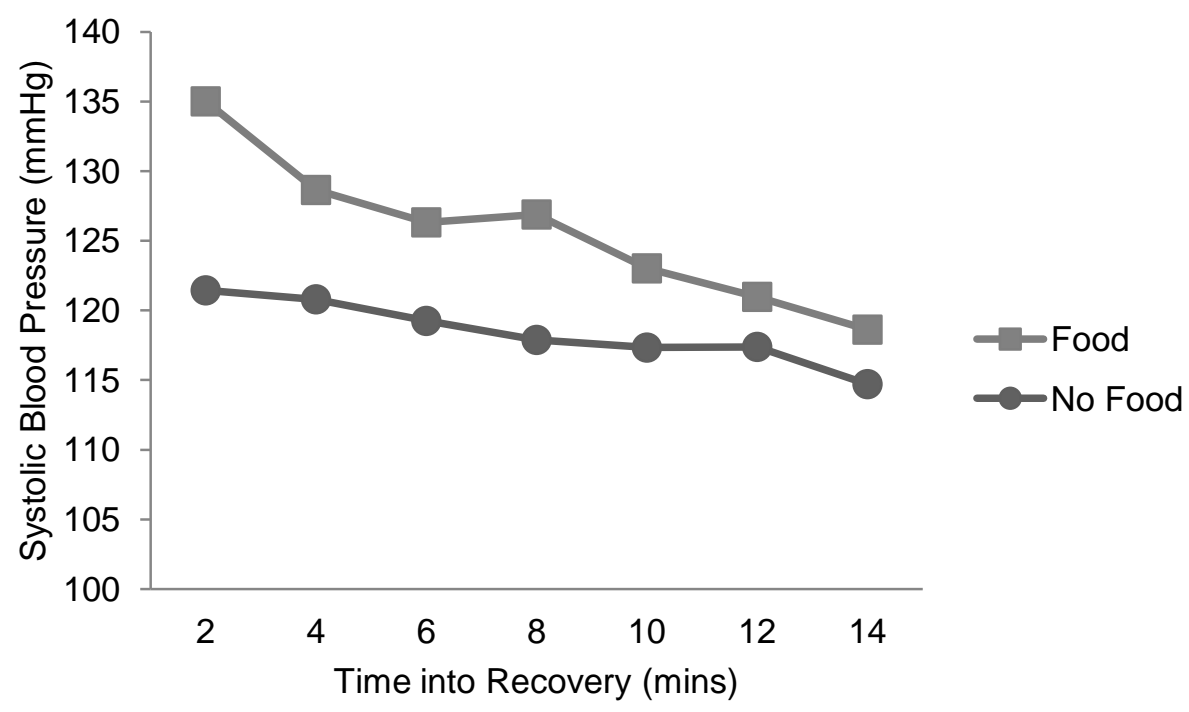

Figure 4. A visualization of systolic blood pressure recovery during Food and No Food sessions; recovery occurred significantly more quickly in the No Food session. 
Table 1

Demographic information for the study sample

\begin{tabular}{|c|c|}
\hline Category & Percentage \\
\hline \multicolumn{2}{|l|}{ Gender } \\
\hline Male & $25 \%$ \\
\hline Female & $75 \%$ \\
\hline \multicolumn{2}{|l|}{ Race } \\
\hline Caucasian & $84.6 \%$ \\
\hline Black or African American & $3.8 \%$ \\
\hline Biracial & $3.8 \%$ \\
\hline Asian & $1.9 \%$ \\
\hline American Indian/Alaskan Native & $1.9 \%$ \\
\hline \multicolumn{2}{|l|}{ BMI } \\
\hline Underweight & $5.7 \%$ \\
\hline Normal & $61.5 \%$ \\
\hline Overweight & $13.5 \%$ \\
\hline Obese & $19.2 \%$ \\
\hline \multicolumn{2}{|l|}{ Years of College } \\
\hline One & $56.3 \%$ \\
\hline Two & $27.1 \%$ \\
\hline Three & $10.4 \%$ \\
\hline Four & $4.2 \%$ \\
\hline Five & $2.1 \%$ \\
\hline \multicolumn{2}{|l|}{ Tobacco Use } \\
\hline Never & $98 \%$ \\
\hline Not Currently & $2 \%$ \\
\hline \multicolumn{2}{|l|}{ Alcohol Use } \\
\hline Never & $16 \%$ \\
\hline Infrequently (a few drinks per year) & $32 \%$ \\
\hline Occasionally (1-2 drinks per month) & $26 \%$ \\
\hline Weekly (1-3 drinks per week) & $14 \%$ \\
\hline Weekly (3-6 drinks per week) & $12 \%$ \\
\hline Daily (7-14 drinks per week) & -- \\
\hline Daily (more than 14 drinks per week) & -- \\
\hline \multicolumn{2}{|l|}{ Caffeine Use (cups per day) } \\
\hline None & $12 \%$ \\
\hline
\end{tabular}


1-2

$28 \%$

3-4

$58 \%$

5-6

$2 \%$

$7-8$

$>8$

$--$

$-$

Exercise Frequency (per week)

Never

$12 \%$

1-2 times

$28 \%$

3-6 times

$58 \%$

7 or more times

$2 \%$

\section{Sleep}

4-5 hours

$8 \%$

5-6 hours

$10 \%$

6-7 hours

$34 \%$

7-8 hours

$36 \%$

8-9 hours

$10 \%$

Greater than 9 hours

$2 \%$ 
Table 2

Correlations between task reactivity measures controlling for resting measures

\begin{tabular}{lllllllll}
\hline & Heart Rate & SBP & DBP & HF HRV & LF HRV & Cortisol & $\begin{array}{l}\text { Pos } \\
\text { Affect } \\
\text { Change }\end{array}$ & $\begin{array}{l}\text { Neg } \\
\text { Affect } \\
\text { Change }\end{array}$ \\
\hline Heart Rate & 1.0 & -.15 & -.28 & -.01 & .10 & -.13 & .22 & .04 \\
SBP & -.26 & 1.0 & .39 & -.11 & -.27 & .25 & -.25 & .04 \\
DBP & $.50 * *$ & $.50 * *$ & 1.0 & -.10 & .08 & .03 & .06 & -.03 \\
HF HRV & .01 & .08 & -.18 & 1.0 & $.45^{*}$ & .13 & .18 & -.29 \\
LF HRV & .05 & .05 & -.16 & $.96 * * *$ & 1.0 & -.27 & .40 & -.36 \\
Cortisol & .31 & .30 & .22 & -.30 & -.37 & 1.0 & $-.50 *$ & .10 \\
$\begin{array}{l}\text { Pos Affect } \\
\text { Change }\end{array}$ & -.30 & -.30 & .02 & -.23 & -.14 & -.06 & 1.0 & -.37 \\
$\begin{array}{l}\text { Neg Affect } \\
\text { Change }\end{array}$ & -.21 & -.21 & -.21 & .14 & .06 & .04 & .23 & 1,0 \\
\hline \multicolumn{1}{c}{$* p<.05, * * p<.01, * * * p<.001$} & & & & & & & & \\
\hline
\end{tabular}

Note. Correlations for task during Food session are below the diagonal and for No Food session are above the diagonal. 
Table 3

Analyses of Variance Demonstrating Reactivity from Rest to Task

\begin{tabular}{|c|c|c|c|c|c|c|}
\hline \multirow[b]{2}{*}{ Measure } & \multicolumn{2}{|c|}{ Rest } & \multicolumn{2}{|c|}{ Task } & \multirow[b]{2}{*}{$F$} & \multirow[b]{2}{*}{$p$} \\
\hline & $\mathrm{M}$ & SD & $\mathrm{M}$ & SD & & \\
\hline \multicolumn{7}{|l|}{ HR (bpm) } \\
\hline Food & 76.2 & 11.6 & 82.1 & 11.3 & & \\
\hline No Food & 76.1 & 11.0 & 82.8 & 13.6 & 20.9 & .00 \\
\hline \multicolumn{7}{|c|}{$\mathrm{SBP}(\mathrm{mm} \mathrm{Hg})$} \\
\hline Food & 115.5 & 11.3 & 136.6 & 14.2 & & \\
\hline No Food & 114.1 & 11.9 & 135.8 & 16.6 & 194.8 & .00 \\
\hline \multicolumn{7}{|c|}{$\mathrm{DBP}(\mathrm{mm} \mathrm{Hg})$} \\
\hline Food & 63.3 & 9.9 & 74.1 & 12.1 & & \\
\hline No Food & 65.1 & 11.8 & 73.2 & 11.2 & 65.4 & .00 \\
\hline \multicolumn{7}{|c|}{ LFHRV $\left(\mathrm{ms}^{2}\right)$} \\
\hline Food & 1330.4 & 990.7 & 2345.5 & 2448.4 & & \\
\hline No Food & 1275.6 & 1617.6 & 2021.7 & 1128.7 & 10.1 & .00 \\
\hline \multicolumn{7}{|c|}{$\operatorname{HFHRV}\left(\mathrm{ms}^{2}\right)$} \\
\hline Food & 1120.9 & 1059.1 & 1284.9 & 1760.3 & & \\
\hline No Food & 1524.8 & 3595.8 & 1159.1 & 1366.5 & 11.3 & .00 \\
\hline \multicolumn{7}{|c|}{ Cortisol (ng/ml) } \\
\hline Food & .46 & .18 & .47 & .23 & & \\
\hline No Food & .48 & .23 & .52 & .29 & 1.16 & .29 \\
\hline
\end{tabular}

Note. Fs reflect the main effect for Task Period (Rest, Task).

Table 4 
Analysis of Variance for sex with area under the curve for cardiovascular and neuroendocrine outcomes

\begin{tabular}{|c|c|c|c|c|c|c|c|c|c|c|}
\hline \multirow[b]{3}{*}{ Measure } & \multicolumn{4}{|c|}{ Men } & \multicolumn{4}{|c|}{ Women } & \multirow[b]{3}{*}{$F$} & \multirow[b]{3}{*}{$P$} \\
\hline & \multicolumn{2}{|c|}{ Task } & \multicolumn{2}{|c|}{ Recovery (AUC) } & \multicolumn{2}{|c|}{ Task } & \multicolumn{2}{|c|}{ Recovery (AUC) } & & \\
\hline & $\mathrm{M}$ & SD & $\mathrm{M}$ & SD & $\mathrm{M}$ & $\mathrm{SD}$ & $\mathrm{M}$ & $\mathrm{SD}$ & & \\
\hline \multicolumn{11}{|l|}{ HR (bpm) } \\
\hline Food & 79.7 & 10.3 & 73.9 & 4470.6 & 83.7 & 11.4 & 3182.19 & 3956.9 & & \\
\hline No Food & 79.2 & 10.0 & -743.6 & 4407.2 & 84.4 & 14.6 & -370.0 & 3758.8 & 2.7 & .10 \\
\hline \multicolumn{11}{|c|}{$\mathrm{SBP}(\mathrm{mmHg})$} \\
\hline Food & 140.8 & 18.3 & 5977.9 & 6187.4 & 134.2 & 11.2 & 7377.2 & 7717.5 & & \\
\hline No Food & 146.0 & 18.5 & -90.6 & 9402.9 & 131.5 & 12.3 & 5083.3 & 5703.9 & 2.8 & .10 \\
\hline \multicolumn{11}{|l|}{ DBP (mmHg) } \\
\hline Food & 69.1 & 13.4 & 6871.4 & 10301.5 & 74.4 & 12.4 & 7162.3 & 7137.6 & & \\
\hline No Food & 73.9 & 7.4 & 3813.4 & 20263.8 & 73.1 & 12.7 & 4240.0 & 5431.5 & .001 & .98 \\
\hline \multicolumn{11}{|c|}{$\operatorname{LFHRV}\left(\mathrm{ms}^{2}\right)$} \\
\hline Food & 1864.4 & 953.2 & 556842.5 & 1114835.2 & 2574.6 & 2903.0 & 54277.9 & 2051095.4 & & \\
\hline No Food & 2180.6 & 1286.5 & $335579 / 09$ & 1026730.8 & 1946.1 & 1071.2 & 313408.8 & 416589.5 & .002 & .96 \\
\hline \multicolumn{11}{|c|}{ HFHRV $\left(\mathrm{ms}^{2}\right)$} \\
\hline Food & 827.5 & 723.4 & 265851.8 & 1012240.2 & 1502.7 & 2063.5 & 597190.1 & 3972552.9 & & \\
\hline No Food & 1282.7 & 1671.5 & -409148.2 & 1701718.2 & 1100.3 & 1238.0 & 154888.8 & 468409.6 & .51 & .48 \\
\hline \multicolumn{11}{|l|}{$\begin{array}{l}\text { Cortisol } \\
\text { (ng/mL) }\end{array}$} \\
\hline Food & .49 & .27 & 37.6 & 93.7 & .48 & .21 & 4.04 & 92.6 & & \\
\hline No Food & .60 & .41 & 62.9 & 195.0 & .51 & .24 & -2.4 & 101.5 & 3.4 & .07 \\
\hline
\end{tabular}

Note. Fs reflect the main effect for Sex of Participant on Recovery in area under the curve units. Task means and SDs are in the units noted. 
Table 5

Hypothesis 1: Descriptive Statistics and Paired t-test Results for Areas Under the Curve (Recovery Rate) for No Food vs. Comfort food sessions

\begin{tabular}{|c|c|c|c|c|c|c|c|c|}
\hline \multirow[b]{2}{*}{ Parameter } & \multicolumn{2}{|c|}{ No Food Control } & \multicolumn{2}{|c|}{ Comfort Food } & \multirow[b]{2}{*}{$\mathrm{n}$} & \multirow{2}{*}{$\begin{array}{l}\text { 95\% CI for Mean } \\
\text { Difference }\end{array}$} & \multirow[b]{2}{*}{$\mathrm{t}$} & \multirow[b]{2}{*}{$\mathrm{Df}$} \\
\hline & $\mathrm{M}$ & SD & $\mathrm{M}$ & SD & & & & \\
\hline Heart Rate & -422.8 & 3835.8 & 2201.1 & 4270.6 & 52 & $1205.1,4042.6$ & $3.72 * * *$ & 48 \\
\hline SBP & 3624.2 & 7001.6 & 6983.2 & 7165.8 & 48 & $1029.1,5688.9$ & $2.9 * *$ & 47 \\
\hline DBP & 4266.3 & 10884.8 & 7020.0 & 7818.0 & 48 & $-1053.1,6560.6$ & 1.455 & 47 \\
\hline LF HRV & $3.19 \times 10^{5}$ & $6.13 \times 10^{5}$ & $5.78 \times 10^{5}$ & $2.52 \times 10^{5}$ & 52 & $-2.1 \times 10^{5}, 7.27 \times 10^{5}$ & 1.12 & 51 \\
\hline HF HRV & 20761.9 & $9.21 \times 10^{6}$ & $5.21 \times 10^{5}$ & $3.37 \times 10^{6}$ & 52 & $-4.31 \times 10^{5}, 1.43 \times 10^{6}$ & 1.079 & 51 \\
\hline Cortisol & 12.5 & 131.8 & 12.6 & 91.3 & 51 & $-43.3,43.3$ & .001 & 50 \\
\hline Pos Affect & .44 & 5.84 & 2.46 & 6.88 & 52 & $-.14,4.18$ & 1.88 & 51 \\
\hline Neg Affect & 4.10 & 5.00 & 3.65 & 4.88 & 52 & $-1.63, .74$ & -.749 & 51 \\
\hline
\end{tabular}

Note: Pos Affect and Neg affect represent results of t-tests comparing affect change scores for Food and No Food sessions (stress - end of recovery) rather than AUC 
Table 6

Hypothesis Three: Individual difference predictors of HR recovery difference scores

\begin{tabular}{lccc}
\hline \multicolumn{1}{c}{ Predictor } & $B$ & $S E B$ & $\mathrm{~B}$ \\
\hline Body Mass Index & -132.3 & 151.7 & -.14 \\
Waist/Hip & -23644.1 & 13956.2 & -.26 \\
Binge Eating & 713.5 & 299.0 & $.40^{*}$ \\
Restricted Eating & -22.7 & 94.7 & -.04 \\
Depression & -105.3 & 79.0 & -.20 \\
\hline
\end{tabular}

Notes: $R^{2}=.15, n s, * p<.05$ 
Table 7

Hypothesis Three: Individual difference predictors of SBP recovery difference scores

\begin{tabular}{lccc}
\hline \multicolumn{1}{c}{ Predictor } & $B$ & $S E B$ & $\mathrm{~B}$ \\
\hline Body Mass Index & 199.6 & 251.4 & .13 \\
Waist/Hip & 4751.9 & 19937.1 & .04 \\
Binge Eating & 787.0 & 552.7 & .27 \\
Restricted Eating & -163.3 & 171.2 & -.17 \\
Depression & 102.8 & 128.6 & .13
\end{tabular}

Notes: $R^{2}=.10, n s, p s>.05$ 
Table 8

Hypothesis Three: Individual difference predictors of DBP recovery difference scores

\begin{tabular}{lccc}
\hline \multicolumn{1}{c}{ Predictor } & $B$ & $S E B$ & $\beta$ \\
\hline Body Mass Index & -65.1 & 419.9 & -.03 \\
Waist/Hip & 6394.4 & 33303.1 & .03 \\
Binge Eating & -1191.4 & 923.2 & -.25 \\
Restricted Eating & -6.4 & 286.0 & -.004 \\
Depression & 36.0 & 214.9 & .03
\end{tabular}

Notes: $R^{2}=.06, n s, p s>.05$ 
Table 9

Hypothesis Three: Individual difference predictors of LF HRV recovery difference scores

\begin{tabular}{lccc}
\hline & $B$ & $S E B$ & $\beta$ \\
\hline Body Mass Index & 394.5 & 53254.9 & .001 \\
Waist/Hip & $-1.9 \times 10^{6}$ & $4.2 \times 10^{6}$ & -.07 \\
Binge Eating & -45868.3 & 101389.6 & -.08 \\
Restricted Eating & 28382.9 & 33343.4 & .14 \\
Depression & -406.0 & 26650.9 & -.002 \\
\hline
\end{tabular}

Notes: $R^{2}=.02, \mathrm{ps}>.05$ 
Table 10

Hypothesis Three: Individual difference predictors of HF HRV recovery difference scores

\begin{tabular}{lccc}
\hline \multicolumn{1}{c}{ Predictor } & $B$ & $S E B$ & $\beta$ \\
\hline Body Mass Index & 39639.0 & 102222.4 & .06 \\
Waist/Hip & $-1.0 \times 10^{7}$ & $8.2 \times 10^{6}$ & -.19 \\
Binge Eating & $-2.9 \times 10^{5}$ & $1.9 \times 10^{5}$ & -.26 \\
Restricted Eating & 30405.5 & 64002.4 & .08 \\
Depression & -23046.5 & 51156.3 & -.07 \\
\hline
\end{tabular}

Notes: $R^{2}=.08, n s, p s>.05$ 
Table 11

Hypothesis Three: Individual difference predictors of salivary cortisol recovery difference scores

\begin{tabular}{lccc}
\hline \multicolumn{1}{c}{ Predictor } & $B$ & $S E B$ & $\beta$ \\
\hline Body Mass Index & 8.8 & 4.6 & .29 \\
Waist/Hip & 333.2 & 361.6 & .14 \\
Binge Eating & 3.39 & 8.6 & .07 \\
Restricted Eating & -4.8 & 2.8 & -.26 \\
Depression & -2.1 & 2.4 & -.13 \\
\hline
\end{tabular}

Notes: $R^{2}=.17, p \mathrm{~s}>.05$ 
Table 12

Exploratory analysis: Partial correlations between measures of dysfunctional eating and weight regulation and stress responses

\begin{tabular}{lcccccc}
\hline & Heart Rate & SBP & DBP & HF HRV & LF HRV & Cortisol \\
\hline BMI & .16 & -.06 & -.1 & .12 & .17 & -.12 \\
WHR & .17 & .01 & -.02 & .16 & .24 & .02 \\
Emotional Eating & -.01 & -.07 & $-.36^{*}$ & .34 & .12 & .03 \\
Restrained Eating & -.05 & .10 & -.25 & .20 & .30 & .20 \\
Binge Eating & .22 & .14 & -.11 & .20 & -.17 & .08 \\
$* p<.05$ & & & & & &
\end{tabular}


Table 13

Types offoods chosen for consumption during the Food session

\begin{tabular}{|c|c|}
\hline Food & Number of Participants \\
\hline Ice Cream & 10 \\
\hline Potato chips & 6 \\
\hline Mac and Cheese & 5 \\
\hline Chocolate & 4 \\
\hline Candy with chocolate & 4 \\
\hline Cookies & 3 \\
\hline Pretzels & 2 \\
\hline White rice w/soy sauce & 2 \\
\hline Fruit & 2 \\
\hline Cake & 2 \\
\hline Cereal & 1 \\
\hline Popcorn & 1 \\
\hline Yogurt & 1 \\
\hline Crackers & 1 \\
\hline Mashed potatoes & 1 \\
\hline Pizza & 1 \\
\hline Spaghetti & 1 \\
\hline French fries & 1 \\
\hline Poptarts & 1 \\
\hline
\end{tabular}




\section{Appendix A}

\section{Demographics Questionnaire}

Participant \#:

Height(in.):

\section{Your Information:}

Your age

Your sex

○ Male

○ Female

Your race

○ Black

$\circ$ White

○ Hispanic

○ Asian

○ Biracial (specify):

o Other

Total years of education you have completed:

$\circ$ High school

$\circ 1$ year college

$\circ 2$ years college

○ 3 years college

- 4 or more years college

Please describe any cardiovascular related illness that you may have, including high blood pressure:

Please list any other medical or psychiatric problems that you have: 
Please list any major surgeries and medical, or psychiatric illnesses you have had in the past.

Females: When did you start your last menstrual cycle?

○ I am a Male

○ less than one week ago

$\circ$ one week ago

○ two weeks ago

$\circ$ three weeks ago

$\circ$ four weeks ago

$\circ$ more than four weeks ago

$\circ$ I am currently pregnant

Females: Are you currently on birth control (contraceptives).

○ I am a male

$\circ$ No

$\circ$ Yes

What type of birth control are you taking?

Please list any drugs (legal or otherwise) that you are currently taking including; birth control (contraceptives), heart medications, cold or allergy medications, over the counter medications, asthma medications, Beta-Blockers (i.e. Inderal, Tenormin), psychoactive drugs (i.e. Adderall, Xanax, Haldol, Lithium, Prozac), or diet pills.

On average, how often do you smoke cigarettes?

o never

○ I am not currently smoking 


$$
\begin{aligned}
& \circ \text { less than one pack per day } \\
& \circ \text { 1-2 packs per day } \\
& \circ \text { 2-3 packs per day } \\
& \circ \text { greater than } 3 \text { packs per day }
\end{aligned}
$$

On average, how often do you use smokeless tobacco?

o never

- I am not currently using smokeless tobacco

○ 1-4 times per day

○ 5-8 times per day

○ 9-13 times per day

$\circ$ greater than thirteen times per day

How often do you drink alcohol?

o never

$\circ$ infrequently (a few drinks per year)

$\circ$ occasionally (1-2 drinks per month)

○ weekly (1-3 drinks per week)

○ weekly (3-6 drinks per week)

○ daily (7-14 drinks per week)

$\circ$ daily (more than 14 drinks per week)

How many cups of caffeinated coffee, tea, or soda do you have per day?

o none

○ 1-2 cups per day

o 3-4 cups per day

- 5-6 cups per day

○ 7-8 cups per day

$\circ$ greater than eight cups per day

About how many caffeinated beverages do you usually have by this time of day? 
How many times per week do you engage in aerobic physical activity?

o never

o 1-2 times

- 3-6 times

○ 7 or more times

For how long do you typically exercise on each occasion?

○ 5-10 minutes

○ 10-15 minutes

o 15-30 minutes

○ 30-60 minutes

o more than 60 minutes

How many hours of sleep did you get last night?

$\circ$ Less than 4 hours

○ 4-5 hours

○ 5-6 hours

○ 6-7 hours

○ 7-8 hours

○ 8-9 hours

$\circ$ greater than 9 hours

\section{Family Information:}

What is your best estimate of your family's total income?

○ Less than 24,999

○ 25,000 to 34,999

○ 35,000 to 49,999

○ 50,000 to 74,999

○ 75,000 to 99,999

○ 100,000 to 149,999 
$\circ$ Greater than 150,000

Approximately how old is your father?

Is he currently living?

$\circ$ yes

○ no

Did/does your father have high blood pressure (hypertension)?

○ yes

○ no

How certain are you that he did, or did not, have high blood pressure (hypertension)?

○ Absolutely (100\%) certain

$\circ$ Almost $(75 \%)$ certain

$\circ$ Not sure at all $(25 \%)$

○ No information by which to judge $(0 \%)$

Did/does your father have any heart problems such as angina (chest pains), a heart attack, or coronary heart disease?

○ yes

○ no

If yes, please specify if you are able:

How certain are you that he did, or did not, have a heart problem as indicated above?

$\circ$ Absolutely (100\%) certain

$\circ$ Almost (75\%) certain

$\circ$ Not sure at all $(25 \%)$

○ No information by which to judge $(0 \%)$

Did/does your father have diabetes?

○ yes

$\circ$ no

How certain are you that he did, or did not, have diabetes? 
○ Absolutely (100\%) certain

$\circ$ Almost $(75 \%)$ certain

$\circ$ Not sure at all $(25 \%)$

○ No information by which to judge $(0 \%)$

Did/does your father have a kidney disease (other than kidney stones)?

o yes

$\circ$ no

How certain are you that he did, or did not, have a kidney disease (other than kidney stones)?

○ Absolutely (100\%) certain

$\circ \operatorname{Almost}(75 \%)$ certain

○ Not sure at all $(25 \%)$

$\circ$ No information by which to judge $(0 \%)$

Did/does your father have cancer?

$\circ$ yes

$\circ$ no

How certain are you that he did, or did not, have cancer?

○ Absolutely (100\%) certain

$\circ$ Almost (75\%) certain

$\circ$ Not sure at all $(25 \%)$

○ No information by which to judge $(0 \%)$

If you know, please list what type(s) of cancer he had? 
Is she currently living?

$\circ$ yes

$\circ$ no

Did/does your mother have high blood pressure (hypertension)?

$\circ$ yes

○ no

How certain are you that she did, or did not, have high blood pressure (hypertension)?

○ Absolutely $(100 \%)$ certain

○ Almost (75\%) certain

$\circ$ Not sure at all (25\%)

○ No information by which to judge $(0 \%)$

Did/does your mother have any heart problems such as angina (chest pains), a heart attack, or coronary heart disease?

○ yes

○ no

If yes, please specify if you are able:

How certain are you that she did, or did not, have a heart problem as indicated above?

○ Absolutely $(100 \%)$ certain

$\circ$ Almost (75\%) certain

$\circ$ Not sure at all $(25 \%)$

○ No information by which to judge $(0 \%)$ 
Did/does your mother have diabetes?

$\circ$ yes

○ no

How certain are you that she did, or did not, have diabetes?

○ Absolutely (100\%) certain

○ Almost (75\%) certain

$\circ$ Not sure at all $(25 \%)$

$\circ$ No information by which to judge $(0 \%)$

Did/does your mother have a kidney disease (other than kidney stones)?

$\circ$ yes

$\circ$ no

How certain are you that she did, or did not, have a kidney disease (other than kidney stones)?

○ Absolutely (100\%) certain

○ Almost (75\%) certain

$\circ$ Not sure at all $(25 \%)$

$\circ$ No information by which to judge $(0 \%)$

Did/does your mother have cancer?

$\circ$ yes

$\circ$ no

How certain are you that she did, or did not, have cancer?

$\circ$ Absolutely $(100 \%)$ certain 
$\circ$ Almost (75\%) certain

$\circ$ Not sure at all (25\%)

$\circ$ No information by which to judge $(0 \%)$

If you know, please list what type(s) of cancer she had? 
Appendix B

Task Instructions: Job Applicant

During this task, you will take on the role of a job applicant who was invited for an interview with a company's managers, who are the selection committee. You will have a preparation period of ten minutes. After this time, you will introduce yourself to the selection committee and convince them that you are the perfect applicant for the available position. Avoice frequency analysis and a video analysis of your performance will be conducted.

Task Instructions: Traffic Ticket

During this task, imagine that you were pulled over by a police officer while driving on the highway. The officer gave you a speeding ticket of $\$ 200.00$ for driving $20 \mathrm{mph}$ over the speed limit. You do not agree with this ticket, and you must appear in court to argue it. You have five minutes to convince the judge that you do not deserve this ticket. A voice frequency analysis and a video analysis of your performance will be conducted. 


\section{Appendix C}

Area Under the Curve Formula Example

Heart Rate:

HR_Sess1_AUC $=(.5 * 60) *\left[\left(H R \_S e s s 1 \_R e c o v e r y \_M i n 1\right)+\left(2 * H R \_S e s s 1 \_R e c o v e r y \_M i n 2\right)+\right.$ (2*HR_Sess1_Recovery_Min3) + (2*HR_Sess1_Recovery_Min4) + (2*HR_Sess1_Recovery_Min5) + (2*HR_Sess1_Recovery_Min6) + (2*HR_Sess1_Recovery_Min7) + (2*HR_Sess1_Recovery_Min8) + $\left(2 * H R \_S e s s 1\right.$ Recovery_Min9) + (2*HR_Sess1_Recovery_Min10) + (2*HR_Sess1_Recovery_Min11) + $\left(2 * H R \_S e s s 1\right.$ Recovery_Min12) + (2*HR_Sess1_Recovery_Min13) + (2*HR_Sess1_Recovery_Min14) + (HR_Sess1_Recovery_Min15)] - (HRSess1_rest_ave * 830) 